\title{
Relation between Sub-grain Size and Dislocation Density During Steady-State Dislocation Creep of Polycrystalline Cubic Metals
}

\author{
Manabu Tamura ${ }^{1}$ \\ ${ }^{1}$ Yokohama, Japan \\ Correspondence: Manabu Tamura, 6-45-2 Hiniminami Konan-ku, Yokohama, 234-0055, Japan. Tel: 81-45-891- \\ 1039. E-mail: mtamura.1943@pep.ne.jp
}

Received: July 11, 2018

doi: $10.5539 / j m s r . v 7 n 4 p 26$
Accepted: July 24, 2018

Online Published: July 26, 2018

URL: https://doi.org/10.5539/jmsr.v7n4p26

\begin{abstract}
The sub-grain size, $d$, during steady-state dislocation creep of polycrystalline metals is theoretically formulated to be inversely proportional to the dislocation density, $\rho$, which is defined as the number of dislocations swept out of a sub-grain divided by the cross-sectional area of the sub-grain. This dislocation density differs from the typically observed dislocation density inside a sub-grain after unloading, $\rho_{\mathrm{ob}}$. In the current work, the $\rho_{\mathrm{ob}}$ values inside sub-grains in steadily crept specimens of $\mathrm{Al}, \mathrm{Cu}, \mathrm{Fe}, \mathrm{Fe}-\mathrm{Mo}$ alloy, austenitic stainless steel, and high-Cr martensitic steel reported in the literature were used to evaluate the relation $\rho_{\mathrm{ob}}=\eta \rho$. It was confirmed that $\eta \approx$ 1 for pure metals (regardless of the type of metal) crept at high temperatures and low stresses or for long durations and $\eta>1$ for Mo-containing alloys and martensitic steel crept at low temperatures and/or high stresses. Moreover, it is suggested that the condition $\eta>1$ corresponds to a state of excess immobile dislocations inside the sub-grain. The theoretical relation $d_{\mathrm{ob}}(\approx d) \propto \eta \cdot \rho_{\mathrm{ob}}{ }^{-1}$, where $d_{\mathrm{ob}}$ is the observed sub-grain size, essentially differs from the well-known empirical relation $d_{\mathrm{ob}} \propto \rho_{\mathrm{ob}}{ }^{-0.5}$.
\end{abstract}

Keywords: dislocation density, sub-grain size, steady-state dislocation creep, deformation at high temperatures, cubic metal

\section{Introduction}

Dislocations accompanied by instantaneous strain directly after loading or dislocations introduced before loading by martensitic transformation or cold working are annihilated or redistributed repeatedly, reducing the total elastic energy and gradually forming a cell structure or sub-grains during transition creep of polycrystalline metals, which is followed by steady-state creep (Hasegawa, Karashima, \& Hasegawa, 1971; Takeuchi \& Argon, 1976; Evangelista, Guardamagna, Kloc, Rosen, \& Spigrarelli, 1995a and 1995b; Sawada, Maruyama, Komine, \& Nagae, 1997; Sedlacek, Blum, Kratochvil, \& Forest, 2002; Kratochvil \& Sedlacek, 2004). For many types of metals, it has been confirmed that the observed average size of the sub-grains $\left(d_{\mathrm{ob}}\right)$ in steady-state creep can be formulated from the applied stress, $\sigma$, using an exponential law (Mukherjee, 1975; Takeuchi \& Argon, 1976; Kassner, 2009)

$$
d_{\mathrm{ob}}=K_{\mathrm{s}} \sigma^{-m}
$$

where $K_{\mathrm{s}}$ and $m$ are constants. It is commonly accepted that $m=1$ for many types of metals and alloys. Raj \& Pharr (1986) collected 66 data sets including those for austenitic stainless steel, ionic structures, and ceramics and obtained a mean value of $m=0.84$; however, the actual value of $m$ varies widely from 0.05 to 1.98 and depends on the chemical composition, grain size, temperature, stress, loading mode, and measurement techniques and in addition they pointed out $K_{\mathrm{s}}$ itself is dependent on $m$. Raj \& Pharr (1986) also evaluated the theoretical models in the literature using limited experimental data sets; however, no theoretical model was fully satisfied. After Raj's review (Raj \& Pharr, 1986), several high-Cr tempered martensitic steels with high creep strength were developed, and their microstructural behaviors during creep were studied in detail. Orlova, Bursik, Kucharova, \& Sklenicka (1998) studied the microstructural development during high-temperature creep of a tempered martensitic steel with high creep strength, $9 \mathrm{Cr}-1 \mathrm{MoVNbN}$ steel (Type 91), and found that the exponent $m$ was low $(\sim 0.24)$ for the duration of creep until rupture at $873 \mathrm{~K}$. Rather low values of $m$ of 0.6-1.0 have also been reported for rupture specimens of high-Cr tempered martensitic steel (Sawada et al., 1997; Kadoya \& Shimizu, 2000; Kadoya, Dyson, \& McLean, 2002) and simple iron alloys (Kadoya \& Shimizu, 2002). Blum \& Straub (1991) imagined a sub-grain with its size, $d_{\text {eq }}$, in a dynamical equilibrium state after infinite creep deformation, assumed $m=1$, and empirically obtained the relation $d_{\mathrm{eq}}=10 \mathrm{~Gb} / \sigma$ using sub-grain size data at large strain $(\varepsilon>0.1)$ instead 
of $d_{\mathrm{eq}}$ for tempered martensitic steel (X20 CrMoV 121 in Deutsche Industrie Normen, hereinafter X20), where $G$ is the shear modulus and $b$ is the length of the Burgers vector. There have been similar discussions on the tempered martensitic steels $11 \mathrm{Cr}-3 \mathrm{~W}, 9 \mathrm{Cr}-1 \mathrm{MoVNbN}$ (Blum \& Gotz,1999), and X20 (Aghajani, Somsem, \& Eggeler, 2009). These findings indicate that $d_{\mathrm{ob}} \propto \sigma^{-1}$ is not a theoretical formula but that Equation 1 presents a simple empirical equation implying unclear variables, as pointed out by Raj \& Pharr (1986). However, many dislocations usually remain inside a sub-grain even in steady state, and the observed dislocation density, $\rho_{\mathrm{ob}}$, during steady-state creep can be formulated from $\sigma$ using an exponential law (Mukherjee, 1975; Takeuchi \& Argon, 1976; Kassner, 2009)

$$
\sigma=K_{\mathrm{d}} \rho_{\mathrm{ob}}{ }^{\ell},
$$

where $K_{\mathrm{d}}$ and $\ell$ are constants. It has been commonly accepted that $\ell=0.5$ for many types of metals and alloys including austenitic stainless steel; however, the actual value of $\ell$ varies widely between 0.45 and 3 and depends on the chemical composition, temperature, stress, loading mode, and measurement techniques (Orlova, Tobolova, \& Cadek, 1972; Mukherjee, 1975; Takeuchi \& Argon, 1976; Kassner, 2004 and 2009). We cannot find a relation such as Equation 2 for steady-state creep or at the minimum creep rate (MCR) for high-Cr tempered martensitic steels with high creep strength; however, $\ell=0.41$ based on Sawada's observed dislocation density data (Sawada et al., 1997) inside a lath structure for ruptured specimens of Type 91 steel and $\ell=0.23$ based on Fedoseeva's observed dislocation density data inside a lath structure for ruptured specimens of $9 \mathrm{Cr}-3 \mathrm{Co}-0.4 \mathrm{Mo}-2 \mathrm{WVNbBN}$ steel (3\% Co-modified Type 92) (Fedoseeva, Dudova, \& Kaibyshev, 2016 ). Moreover, $\ell=0.27$ based on Hayakawa's data (Hayakawa, Terada, Yoshida, Nakashima, \& Goto, 2003) for Type 91 specimens crept to a strain near the MCR with the use of the mobile dislocation density calculated using the stress change test (SCT) method instead of $\rho_{\mathrm{ob}}$. These values of $\ell$ for high-Cr steels are rather low compared with the values stated earlier, i.e., $\ell=0.45-3$. Although Equation 2 with $\ell=0.5$ is similar to equations based on work-hardening theories (Otte \& Hren, 1966), to understand creep phenomena, internal stress and recovery should also be considered (Chen, Flewitt, Cocks, \& Smith, 2015). Therefore, the models proposed in work-hardening theories (Otte \& Hren, 1966) cannot be applied to creep phenomena or it is clear that an expression such as Equation 2 is not a theoretical equation but a simple empirical one.

By eliminating the stress term from Equations 1 and 2, we can obtain the relation

$$
d_{\mathrm{ob}}=K_{\mathrm{sd}} \rho_{\mathrm{ob}}{ }^{-j},
$$

where $K_{\mathrm{sd}}$ and $j=m \times \ell$ are constants. Using the commonly accepted values of $m=1$ and $\ell=0.5$, we obtain $j=0.5$ or the generally accepted relation $d_{\mathrm{ob}} \propto \rho_{\mathrm{ob}}{ }^{-0.5}$. However, the value of $j$ varies widely from 0.3 to 1.0 for $\mathrm{Al}, \mathrm{Cu}, \mathrm{Fe}, \mathrm{Fe}-\mathrm{Mo}$, and stainless steel using data summarized by Takeuchi \& Argon (1976), which were obtained by the same author(s) who used transmission electron microscopy (TEM) to minimize the uncertainty of the calculated $j$ value. The relation $d_{\mathrm{ob}} \propto \rho_{\mathrm{ob}}{ }^{-0.5}$ was experimentally confirmed by Holt (1970) for Fe and by Toriumi (1979) for the naturally deformed olivine structure of non-metal polycrystalline materials. Orlova \& Cadek (1973) also confirmed this relation for Fe, Al, and $\mathrm{Zr}$ and showed that the $\mathrm{Fe}$ and $\mathrm{Al}$ data formed a single data band but that the data for $\mathrm{Zr}$ appeared separately from the $\mathrm{Fe}$ and $\mathrm{Al}$ data band. Dudko, Belyyakov, \& Kaibyshev (2017) confirmed the relation $d_{\mathrm{eq}} \propto \rho_{\mathrm{ob}}{ }^{-0.5}$ during acceleration creep of Type P92 steel. Similarly, the relation of Equation 3 has been confirmed for specified data; however, a comparison of Equation 3 using data sets for many types of materials obtained under the same test conditions has not yet been performed. In this work, in order to reduce the uncertainty of the results I first collected data sets of cell or sub-grain size, $d_{\mathrm{ob}}$, and dislocation density inside a cell or sub-grain, $\rho_{\mathrm{ob}}$, which were reported together in a single paper and were based on measurements. Furthermore, the data were limited to specimens deformed in steady state and only measurements performed using TEM were collected to reduce data scattering, as the dislocation density is largely affected by the measurement technique applied (Tamura, 2017). As a result, only data for metals without a hexagonal structure were selected.

Holt (1970) provided a theoretical explanation for the relation $d_{\mathrm{ob}} \propto \rho_{\mathrm{ob}}{ }^{-0.5}$; however, his explanation cannot be applied to creep because recovery and annihilation of dislocations were not considered. It is clear that Equation 3 is a simple correlation equation that does not contain independent variables, such as temperature and stress, and thus, an in-depth discussion of this equation may not be necessary, as pointed out by Kassner (2009). However, a plot of $d_{\mathrm{ob}}$ vs. $\rho_{\mathrm{ob}}$ for many materials, which will be introduced in a later section, results in the formation of a single and relatively narrow data band that is independent of the material type and test conditions. Therefore, the meaning of Equation 3 requires further discussion.

In this paper, first, a theoretical equation describing the relation between the dislocation density $(\rho)$ and sub-grain size $(d)$ during steady-state creep of polycrystalline metals is introduced based on simple assumptions, where the 
dislocation density, $\rho$, is defined as the number of dislocations swept out of a sub-grain divided by the crosssectional area of the sub-grain (defined in a discussion section) and is the dislocation density necessary for creep deformation. This definition of $\rho$ differs from the observed dislocation density, $\rho_{\mathrm{ob}}$, even during steady-state creep. Then, the meaning of the differences between the data collected from the literature for $d_{\mathrm{ob}}$ and $\rho_{\mathrm{ob}}$ and the proposed theoretical equation is discussed.

In the theoretical analysis, only dislocation creep is considered, because the collected data were obtained at moderate temperatures, namely $T / T_{\mathrm{m}}$ values ranging from 0.39 to 0.79 (except for the lowest value of 0.22 for $\mathrm{Cu}$ ), where $T$ and $T_{\mathrm{m}}$ are the test temperature and melting temperature for each metal (in Kelvin), respectively. In the calculation for alloy, the melting temperature of a base metal was used as a melting temperature of each alloy.

The data were obtained under rather high stresses, namely, $\sigma / G$ values ranging from $7.8 \mathrm{E}-4$ to $4.73 \mathrm{E}-3$. The grain sizes for all of the collected data were of conventional size (on the order of several tens of micrometers). Under these test conditions, dislocation creep is considered to be dominant (Frost \& Ashby, 1982), provided that the creep mechanism map for pure iron also applies to high-Cr martensitic steel, as a creep mechanism map for high-Cr martensitic steel is not available.

\section{Theoretical Considerations}

\subsection{Dislocation Density Necessary for Steady-State Creep Strain}

First, we imagine a virtual domain of a quadrangular prism, $\mathrm{D}_{\mathrm{m}}$, the cross-section of which is $d_{\mathrm{m}} \times d_{\mathrm{m}}$, in a twodimensional polycrystalline body. The body is deformed steadily under a uniaxial tensile load along one side of the cross section of the prism. A single slip system is activated in $\mathrm{D}_{\mathrm{m}}$, and $n_{0}$ dislocations are steadily swept out of $\mathrm{D}_{\mathrm{m}}$, including non-conservative motions within the time interval $\Delta t$. As a result, a plastic strain of $\varepsilon_{\mathrm{v}}$ is developed in the domain. The tensile plastic strain $\varepsilon_{\mathrm{v}}$ developed within $\Delta t$ and $\rho$ necessary to achieve a strain of $\varepsilon_{\mathrm{v}}$ are defined as

and

$$
\rho=n_{0} / d_{\mathrm{m}}^{2}
$$

$$
\varepsilon_{\mathrm{v}}=M n_{0} b / d_{\mathrm{m}}=M b d_{\mathrm{m}} \rho .
$$

Here, $M$ is a conversion factor from shear strain to tensile strain. Similar plastic deformation occurs throughout a polycrystalline metal; although the slip direction in each domain differs, Equations 4 and 5 hold in a whole specimen in virtual space.

However, each domain in real space that corresponds to a sub-grain in an actual polycrystalline metal is forbidden from freely deforming because of the plastic constraint from the surrounding sub-grains. In real space, multiple slip systems are activated, and extrusion and/or intrusion may occur within $\Delta t$. Therefore, the tensile creep strain of each sub-grain within $\Delta t$ in real space is smaller than the strain $\varepsilon_{\mathrm{v}}$ described in Equation 5. The tensile creep strain of each sub-grain in real space should be equal to the observable strain increment, $\varepsilon_{\text {inc }}$, within $\Delta t$ because the macroscopic strain for each sub-grain is constant throughout the entire cross-section of a specimen as long as grain boundary sliding can be ignored. In this report, only dislocation creep is considered. Therefore, we obtain the following equations from Equation 5 using the parameter $\alpha$ :

and

$$
\varepsilon_{\text {inc }}=\alpha \varepsilon_{\mathrm{v}}=\alpha M b d_{\mathrm{m}} \rho
$$

Equation 6 can be rewritten as

$$
\alpha=\varepsilon_{\text {inc }} / \varepsilon_{\mathrm{v}}<1
$$

$$
\varepsilon_{\text {inc }}=M b\left(\alpha d_{\mathrm{m}}\right) \rho .
$$

Comparing Equation 8 with Equation 5, we find that Equation 8 indicates that in real space, an area with a value of $\alpha d_{\mathrm{m}} \times \alpha d_{\mathrm{m}}$ is strained by $\varepsilon_{\text {inc }}$ along the tensile axis within $\Delta t$, where $\rho$ in Equation 8 is given by Equation 4. Equation 4 can be rewritten as

$$
\rho=n_{0} / d_{\mathrm{m}}{ }^{2}=\alpha^{2} n_{0} /\left(\alpha d_{\mathrm{m}}\right)^{2} .
$$

Therefore, we can confirm that the number of dislocations swept out of an area $\alpha d_{\mathrm{m}}$ in real space decreases to $\alpha^{2} n_{0}$ from $n_{0}$ in virtual space. However, $\rho$ necessary for an observable $\varepsilon_{\text {inc }}$ within $\Delta t$ is really the same as that for Equation 4 for virtual space. 


\subsection{Formulation of $\rho_{o b}$ Using $d_{o b}$}

Plastic deformation due to dislocation creep is caused by dislocations swept out of a crystal; in other words, plastic deformation cannot be generated only by the movement of dislocations within a crystal (Cottrell, 1964). Therefore, $\rho$ is surely proportional to $\varepsilon_{\text {inc }}$ within $\Delta t$, as described in Equation 6 because we can apply the above statement to all sub-grains in a polycrystalline metal. Ashby (1970) discussed the plasticity of polycrystals in general and showed that if a single slip system is activated in each grain, overlap and voids appear near the boundaries. To avoid these situations, he punctuated the necessity of geometrically necessary dislocations stored in each grain, $\rho^{\mathrm{G}}$, to explain work hardening at low temperatures and introduced the formulation $\rho^{G} \propto \bar{\epsilon}$, where $\bar{\epsilon}$ is the tensile strain. During steady-state creep, work hardening does not occur, and thus, dislocations accumulated near the boundaries interact with and/or annihilate each other together with dislocations swept out of the neighboring subgrains, which leads to rotation of each sub-grain or local deformation near the boundaries and preserves the continuity of a body.

In addition to $\rho$, there is also the dislocation density actually existing in a sub-grain during steady-state creep, $\rho_{\mathrm{sb}}$, which can be further broken down into the mobile and sessile dislocation densities inside a sub-grain, $\rho_{\mathrm{sbm}}$ and $\rho_{\text {sbs }}$, respectively. Furthermore, the observable dislocation density, $\rho_{\text {ob }}$, also differs from $\rho_{\text {sb }}, \rho_{\text {sbm }}, \rho_{\text {sbs }}$, and $\rho$. $\rho_{\text {ob }}$ can be determined using TEM to quantify the dislocations distributed in a thin film prepared near room temperature in a crept specimen after unloading and removing sensible heat. Even if a crept specimen is cooled as rapidly as possible, relaxation should still occur during cooling. Using these phenomena, the internal stresses can be calculated (Norman Ahlquist \& Nix, 1969; Solomon, 1969; Yoshinaga, Toma, \& Morozumi, 1974; Abe, Yoshinaga, \& Morozumi, 1976). As these relaxation phenomena are clearly observed even within only 1 or $2 \mathrm{~s}$ after reducing the stress (Toma, Yoshinaga, \& Morizumi, 1975), it is reasonable to consider that redistribution of dislocations may occur during unloading after creep. Moreover, after creep straining, annihilation of dislocations and recovery should occur because of the sensible heat of a specimen. Namely, it is again confirmed that $\rho_{\text {ob }}$ differs from $\rho_{\mathrm{sb}}\left(=\rho_{\mathrm{sbm}}+\rho_{\mathrm{sbs}}\right)$ just before unloading. Hayakawa et al. (2007) reported $\rho_{\mathrm{ob}}$ and $\rho_{\mathrm{sbm}}$ values near the MCR at $873 \mathrm{~K}$ and $923 \mathrm{~K}$ for $1 \mathrm{Cr}-0.5 \mathrm{Mo}$ steel in a fully annealed condition. These values were obtained using TEM and the SCT method, respectively, and $\rho_{\mathrm{ob}}$ was approximately one order of magnitude higher than $\rho_{\mathrm{sbm}}$. They explained the difference between $\rho_{\mathrm{ob}}$ and $\rho_{\mathrm{sbm}}$ as being caused by the immobile dislocations inside a sub-grain. Based on the above discussion, it is clear that $\rho, \rho_{\mathrm{sbm}}, \rho_{\mathrm{sbs}}, \rho_{\mathrm{sb}}=\rho_{\mathrm{sbm}}+\rho_{\mathrm{sbs}}$, and $\rho_{\mathrm{ob}}$ are fundamentally independent variables, though the approximation $\rho_{\mathrm{ob}} \approx \rho_{\mathrm{sb}}$ may be possible for high densities of immobile dislocations inside a sub-grain.

Sub-grains begin to form during the transition creep stage, and their average size gradually increases until reaching a certain value and then remains constant during steady-state creep (Hasegawa et al., 1971; Kassner, 2009). Subboundaries are considered to be more stable than a dislocation structure inside a sub-grain because sub-boundaries are formed by mutual reactions of swept-out dislocations during creep and, in some cases, dislocation networks are formed. Therefore, if we assume that these sub-boundaries are not greatly affected by unloading and/or heat release, $d_{\mathrm{ob}}$ can be regarded as the size of existing sub-grains, $d$, during creep. Thus, because $d$ is equivalent to $\alpha d_{\mathrm{m}}$ in Equation 8, we obtain

$$
\alpha d_{\mathrm{m}}=d \approx d_{\mathrm{ob}}
$$

$\rho$ in Equation 8 can be determined using a set of creep rate data in some cases (Tamura \& Abe, 2015; Tamura, 2017), and therefore, verification of Equation 8 may be feasible using creep data; however, this verification will be addressed in the future. The aim of the current study is to discuss the relation between the empirical formula in Equation 3 and the theoretical formula in Equation 8. Accordingly, if we define the relation

$$
\rho_{\text {ob }}=\eta \rho,
$$

we obtain the following relation from combining Equations 8, 10, and 11:

$$
d_{\mathrm{ob}}=\eta \varepsilon_{\mathrm{inc}} / M b \cdot \rho_{\mathrm{ob}}{ }^{-1} \text {. }
$$

This formula is essentially different from Equation 3 and is also a general formula that can be applied to all materials.

When Equation 6 was rewritten as Equation $8, \varepsilon_{\text {inc }}=M b\left(\alpha d_{\mathrm{m}}\right) \rho$, the constraint effect was applied only to the domain size, $d_{\mathrm{m}}$, and the relation $d=\alpha d_{\mathrm{m}}$ was obtained (Equation 10). However, the effect of the strain constraint can be converted into both $d_{\mathrm{m}}$ and $\rho$. In this case, we assume a relation $\varepsilon_{\text {inc }}=M b\left(\alpha_{1} d_{\mathrm{m}}\right) \cdot\left(\alpha_{2} \rho\right)$, where $\alpha=\alpha_{1} \alpha_{2}$. When the formula is rewritten as $\varepsilon_{\text {inc }} / \alpha_{2}=M b\left(\alpha_{1} d_{\mathrm{m}}\right) \rho$, because the left side of $\varepsilon_{\text {inc }} / \alpha_{2}$ is arbitrary, this relation is observed to be equivalent to Equation 8 . Therefore, the above developments of Equations 4-9 are sufficient. 
By the way, Equation 12 is rewritten as $\dot{\varepsilon}=M \rho b v$ using Equation 11, if we assume the strain rate and dislocation velocity as $\dot{\varepsilon}=\varepsilon_{\mathrm{inc}} / \Delta t$ and $v=d_{\mathrm{ob}} / \Delta t$, respectively. This relation $\dot{\varepsilon}=M \rho b v$ is well known Orowan's equation (Orowan, 1940). Therefore, it may be necessary to eliminate redundancy in the above developments of Equations 4-12. However, in the above short cut approach the physical meaning of the velocity $v=d_{\mathrm{ob}} / \Delta t$ is unclear. Moreover, Orowan's equation is a general equation describing the flow rate of a crystal, not a polycrystalline, due to the glide motion of dislocations, which include all dislocations not only swept out of a crystal, but also stayed in a crystal. Therefore, in this study, the observable values of $d_{\mathrm{ob}}, \varepsilon_{\text {inc }}$, and $\rho_{\mathrm{ob}}$ in a polycrystalline were correlated with each other in an obvious manner using one parameter, $\eta$.

To further investigate the details of Equation 12, the value of $\varepsilon_{\text {inc }}$ should be determined. Although we can arbitrarily set a value of $\varepsilon_{\text {inc }}$ based on the definition provided in Equation 6, we must remember that the strain range of steady-state creep of heat resistant steel for power boilers is not so large (National Institute for Materials Science [NIMS], 2007). Therefore, although MCRs are usually used for these materials as steady-state creep rates, the accuracy of the observed MCR decreases when the value of $\varepsilon_{\text {inc }}$ is set to be too small. Considering these circumstances, it is reasonable in an engineering sense to set $\varepsilon_{\text {inc }}=0.2 \%$, the value that is used to determine proof stresses. With this consideration, the value of $\rho$ necessary for creep deformation is that necessary to achieve the minimum creep strain while keeping the dislocation structure constant during steady-state creep. Using Equation 12 and $\varepsilon_{\text {inc }}=0.002$, we obtain

$$
d_{\mathrm{ob}}=0.002 \eta / M b \cdot \rho_{\mathrm{ob}}{ }^{-1} .
$$

As discussed above, the physical meaning of $\eta$ in Equation 11, which is necessary to investigate the meaning of Equation 13, cannot be clearly defined, because $\rho$ and $\rho_{\text {ob }}$ are independent variables. However, we can discuss the meaning of $\eta$ from a metallurgical viewpoint by substituting $d_{\mathrm{ob}}$ and $\rho_{\mathrm{ob}}$ values for typical materials into Equation 13.

\section{Observed Values for $\boldsymbol{d}_{\mathrm{ob}}$ and $\rho_{\mathrm{ob}}$}

When the observed values for $d_{\mathrm{ob}}$ and $\rho_{\mathrm{ob}}$ are compared with Equation 13, their uncertainty should be minimized. For this purpose, the following data-selection policy was imposed, as described in detail in Section I: only data for polycrystalline metals that were deformed at moderate temperatures under rather high stresses, where dislocation creep is considered to be the dominant mechanism, were selected; in addition, the $d_{\mathrm{ob}}$ and $\rho_{\mathrm{ob}}$ data had to be reported together in a single paper for specimens deformed steadily and for which the detailed experimental procedures were provided; finally, only data for which the dislocation density was determined using TEM were included. Using these constraints, data for Al (Orlova et al., 1972; Wetter, 1986), Cu (Staker \& Holt, 1972), Fe (Karashima, Iikubo, Watanabe, \& Oikawa, 1971; Orlova \& Cadek, 1973), Fe-4\%Mo alloy (Fuchs \& Ilschner, 1969), austenitic stainless steel (Cuddy, 1970; Challenger \& Moteff, 1973; Michel, Moteff, \& Lovell, 1973; Kassner, Miller, \& Sherby, 1982), and high-Cr martensitic steel (Straub, Meter, Ostermann, \& Blum, 1993; Sawada et al., 1997; Aghajani Bazazi, 2009; Dudova, Plotnikova, Molodov, Belyakov, \& Kaibyshev, 2012; Dudko et al., 2017) were selected and data for metals with a hexagonal structure were excluded.

\subsection{Aluminum}

Orlova et al. (1972) determined the $\rho_{\text {ob }}$ values inside sub-grains of pure Al steadily crept at $573 \mathrm{~K}$ under applied stresses of 3.9-17.2 MPa up to a strain of $\varepsilon \sim 0.2$ followed by rapid cooling. The creep rate for an applied stress of 12.3 MPa was $0.78 \mathrm{~h}^{-1}$, which is high. These researchers also evaluated the temperature dependence of $\rho_{\text {ob }}$ under an applied stress of 12.3 MPa. Wetter (1986) determined $\rho_{\text {ob }}$ inside sub-grains of pure Al steadily deformed at $644 \mathrm{~K}$ under an applied equivalent (tensile) stress of $6.4 \mathrm{MPa}$ (converted from torsional stress) up to a strain of $\varepsilon=16.3$. In Figure 1, the $d_{\mathrm{ob}}$ and $\rho_{\mathrm{ob}}$ data for $\mathrm{Al}$ are plotted; however, only the data that Wetter obtained at $\varepsilon=0.2$ is plotted for comparison with Orlova's data $(\varepsilon \sim 0.2)$. According to Orlova's data, $d_{\mathrm{ob}}$ decreases and $\rho_{\mathrm{ob}}$ increases with increasing stress, as predicted by Equations 1 and 2, and the temperature dependence of the sub-grain size is unclear, as pointed out by Takeuchi \& Argon (1976). Unexpectedly, the dislocation density at high temperatures was high; however, this behavior may be caused by the increase in strain rate that occurs by increasing the temperature under the same stress. The value of $j$ in Equation 3 is 0.48 for all the data plotted in Figure 1.

Fujita, Kawasaki, Furubayashi, Kajiwara, \& Taoka (1967) investigated the total dislocation density $\left(\rho_{\mathrm{t}}\right)$ of heavily rolled pure Al specimens as a function of foil thickness using ultra-high-voltage TEM. They reported that a foil thickness greater than $0.7 \mu \mathrm{m}$ is necessary to attain $\rho_{\mathrm{t}}$ values in the $1 \mathrm{E} 13 \mathrm{~m}^{-2}$ range because the image force acting on dislocations near surfaces during the preparation of foils at ambient temperature causes dislocations to escape from the surfaces (Fujita et al., 1967; Hull \& Bacon, 2011). However, a thin foil of approximately $0.2 \mu \mathrm{m}$ is sufficient to achieve $\rho_{\mathrm{t}}$ values greater than $1 \mathrm{E} 14 \mathrm{~m}^{-2}$ (Fujita et al., 1967). Orlova \& Cadek (1973) reported 
that for crept specimens of pure $\mathrm{Al}$ and $\mathrm{Fe}, \rho_{\mathrm{ob}}$ inside the sub-grains was approximately $10 \%$ of $\rho_{\mathrm{t}}$. Based on Orlova's results and to ensure the validity of the measured $\rho_{\text {ob }}$ for Al, Fujita's finding can be interpreted as follows: $\rho_{\mathrm{ob}}$ inside a sub-grain should be greater than $1 \mathrm{E} 12 \mathrm{~m}^{-2}$ for a foil thickness of $0.7 \mu \mathrm{m}$ or greater than $1 \mathrm{E} 13 \mathrm{~m}^{-2}$ for a foil thickness of $0.2 \mu \mathrm{m}$. However, in Orlova's report (Orlova et al., 1972), the foil thickness is not indicated, and therefore, we cannot directly judge the validity of the data. However, we can estimate the validity of Orlova's data using Wetter's data: Wetter measured the dislocation density using a 1- $\mu \mathrm{m}$-thick foil (Wetter, 1986). Because he used a sufficiently thick foil, his data are considered valid based on the work of Orlova \& Cadek (1973) and Fujita et al. (1967). The test conditions used to obtain Orlova's data in Figure 1 were similar to those used to obtain Wetter's data, and the $\rho_{\text {ob }}$ values for both data sets are similar. Therefore, Orlova's data may not have been affected by the foil thickness.

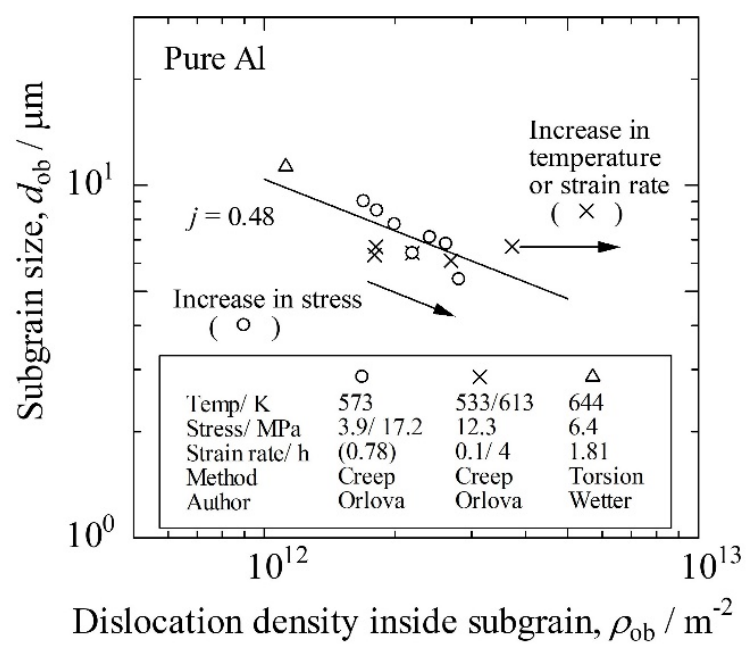

Figure 1. Correlation between $d_{\mathrm{ob}}$ and $\rho_{\mathrm{ob}}$ inside sub-grains in steadily crept specimens of pure Al. A regression line is drawn for all data plotted

\subsection{Copper}

Staker \& Holt (1972) performed tensile tests on pure $\mathrm{Cu}$ at $298-973 \mathrm{~K}$ and $\dot{\varepsilon}=0.3 \mathrm{~h}^{-1}$, which is rather high, and measured flow stresses ranging from 157 to $21 \mathrm{MPa}$ at $\varepsilon=0.1$. Sub-grains were only observed in polycrystalline $\mathrm{Cu}$ at high temperatures; their formation was difficult at low temperatures. Therefore, the total dislocation density, $\rho_{\mathrm{t}}$, of the cell structure in the deformed specimens was evaluated using TEM. The plotted data in Figure 2 are the values reported as total dislocation density and sub-grain size in Staker's paper. $d_{\mathrm{ob}}$ decreases and $\rho_{\mathrm{t}}$ increases with increasing stress (or decreasing temperature), as predicted by Equations 1 and 2. Staker \& Holt (1972) reported that the dislocation density belonging to the cell wall, $\rho_{\mathrm{cw}}$, is 3-4 times larger than the average $\rho_{\mathrm{t}}$. To unify the meaning of dislocation density with $\rho_{\mathrm{ob}}$ inside a cell or sub-grain, the observed dislocation density inside a cell or sub-grain $\left(\rho_{\mathrm{ob}}\right)$ was estimated from TEM images of the deformed specimens provided by Staker \& Holt (1972); we estimated the average cell wall area fraction to be approximately $20 \%$ using this approach.

Assuming a circular cell with diameter $d_{\mathrm{c}}$ and wall thickness $2 t_{\mathrm{w}}$, we obtain the relation $\rho_{\mathrm{t}} d_{\mathrm{c}}{ }^{2}=$ $\rho_{\mathrm{cw}}\left[d_{\mathrm{c}}{ }^{2}-\left(d_{\mathrm{c}}-2 t_{\mathrm{w}}\right)^{2}\right]+\rho_{\mathrm{ob}}\left(d_{\mathrm{c}}-2 t_{\mathrm{w}}\right)^{2}$ based on the number balance of dislocations. Furthermore, we assume the relation of $\rho_{\mathrm{cw}}=3.5 \rho_{\mathrm{t}}$ and $\left[d_{\mathrm{c}}{ }^{2}-\left(d_{\mathrm{c}}-2 t_{\mathrm{w}}\right)^{2}\right] / d_{\mathrm{c}}{ }^{2}=0.2$. Based on the aforementioned findings, we can estimate $\rho_{\text {ob }}$ inside a cell to be approximately $37.5 \%$ of the reported $\rho_{\mathrm{t}}$. The broken line in Figure 2 represents the regression line for the $\rho_{\mathrm{ob}}$ values inside a cell or sub-grain. The slope of the regression line, namely the value of $j$ in Equation 3, is 0.5. Staker \& Holt (1972) used thin foils with thicknesses of $200 \mathrm{~nm}$ and judged that the results were not affected by image forces because the cell structures were well developed.

Although Jones \& Sellars (1970) also reported sub-grain size and dislocation density data measured using an Xray technique and etch pit technique, respectively, their data are not plotted in Figure 2 to unify the meaning of data in this study. 


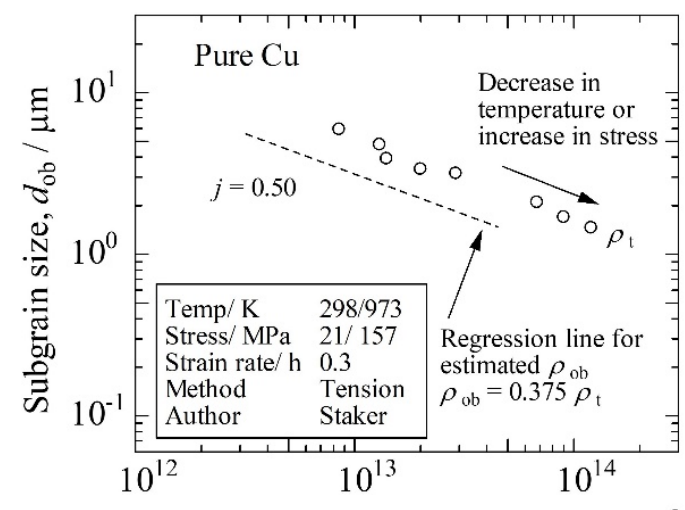

Dislocation density incide cell, $\rho_{\mathrm{ob}} / \mathrm{m}^{-2}$

Figure 2. Correlation between $d_{\mathrm{ob}}$ and $\rho_{\mathrm{ob}}$ inside cells in steadily crept specimens of pure $\mathrm{Cu}$. The total dislocation density values, $\rho_{\mathrm{t}}$, were measured, and $\rho_{\mathrm{ob}}$ was estimated from $\rho_{\mathrm{t}}$ using the method described in the text. The regression line is shown

\subsection{Alpha-Iron and Fe-Mo Alloy}

Karashima et al. (1971) performed a set of creep tests on pure iron at $973 \mathrm{~K}$ under applied stresses of 10-39 MPa and from $923 \mathrm{~K}$ at an applied stress of $18 \mathrm{MPa}$ to $1123 \mathrm{~K}$ at an applied stress of $5 \mathrm{MPa}$ with a constant $\sigma / E$, where $E$ is Young's modulus; they determined the $\rho_{\text {ob }}$ values inside sub-grains in 500 -nm-thick foils using TEM. The carbon content and grain size were determined to be $40 \mathrm{ppm}$ and $80 \mu \mathrm{m}$, respectively. Figure 3 presents the subgrain size results for the steadily crept specimens up to a strain of 0.2 . The strain rate at $973 \mathrm{~K}$ and $13.7 \mathrm{MPa}$ was $0.1 \mathrm{~h}^{-1}$, which is rather high. Other $\rho_{\mathrm{ob}}$ data inside sub-grains with the sub-grain size determined by Orlova $\&$ Cadek (1973) are also plotted in Figure 3 for alpha-Fe crept to a steady state at $773 \mathrm{~K}$ under an applied stress of $36 \mathrm{MPa}$ and at $873 \mathrm{~K}$ under an applied stress of $219 \mathrm{MPa}$. However, the material purity, foil thickness, and creep rate are unknown. Experimental error due to image forces acting on dislocations is negligible for Karashima's data because sufficiently thick foils were used for the TEM observations. Fujita et al. (1967) also showed that the range of the image force effect is rather small (less than $50 \mathrm{~nm}$ ) for pure Fe with a body-centered cubic (BCC) structure during handling of foils at ambient temperature because the dislocations are locked by carbon atoms at a concentration of only $5 \mathrm{ppm}$. Therefore, Orlova's data may also be considered to be close to the $\rho_{\text {ob }}$ values inside sub-grains in bulk specimens. Regression lines for Karashima's and Orlova's data are given in Figure 3, and the values of $j$ are 0.46 and 0.67 , respectively. Both Karashima's and Orlova's data demonstrate that the effects of stress on $d_{\mathrm{ob}}$ and $\rho_{\mathrm{ob}}$ are more pronounced than those of temperature, as pointed out in previous reports (Mukherjee, 1975; Takeuchi \& Argon, 1976; Kassner, 2009). However, there appears to be a large difference between Karashima's and Orlova's data. Although Orlova's data were obtained at lower temperatures and higher stresses than Karashima's data and no data were obtained under the same conditions, the differences cannot be explained by the differences in test conditions alone. The root causes for these differences are unknown.

Karashima, Iikubo, \& Oikawa (1972) performed a set of creep tests on alpha-iron single crystals at 873-1073 K under stresses ranging from 6.5 to $24.5 \mathrm{MPa}$ and determined the values of $d_{\mathrm{ob}}$ and $\rho_{\mathrm{ob}}$ inside sub-grains in steadily crept specimens using TEM. The results are presented in Figure 3 as cross marks and the value of $j$ is 1.1 , which is rather high. Although citing the results of single crystals is outside the scope of this study, it is interesting to investigate the data in terms of the grain size effect. The $d_{\mathrm{ob}}$ and $\rho_{\mathrm{ob}}$ values of polycrystalline and singlecrystal iron are $10.5 \mu \mathrm{m}, 2.5 \mathrm{E} 12 \mathrm{~m}^{-2}$ and $16.7 \mu \mathrm{m}, 6.5 \mathrm{E} 11 \mathrm{~m}^{-2}$, respectively under the same test conditions of $973 \mathrm{~K}$ and 13.7 MPa. Namely, the sub-grain of the single crystal was larger than that of polycrystalline iron and the dislocation density inside the sub-grains of the single crystal was considerably smaller than that of polycrystalline iron. These findings suggest that the plastic constraint of polycrystals is larger than that of single crystals or that $\alpha$ in Equation 7 is smaller or the constraint effect is larger in fine-grain metal.

Fuchs \& Ilschner (1969) determined $d_{\mathrm{ob}}$ and $\rho_{\mathrm{ob}}$ in steadily crept specimens of Fe-4\%Mo alloy at $1021 \mathrm{~K}$ under stresses of 39-98 MPa and at $1098 \mathrm{~K}$ under stresses of 19-47 MPa. The results are plotted in Figure 3. The foil thickness was not reported; however, the dislocation densities of this alloy were higher than those for Karashima's data; therefore, the data is considered reliable. The effects of stress on $d_{\mathrm{ob}}$ and $\rho_{\mathrm{ob}}$ are more pronounced than those of temperature, as pointed out in previous works (Mukherjee, 1975; Takeuchi \& Argon, 1976; Kassner, 
2009). The stress dependences of $d_{\mathrm{ob}}$ and $\rho_{\mathrm{ob}}$ are similar to those of the other materials, as expected from Equations 1 and 2. The value of $j$ is 0.36 . The strain rate at $1021 \mathrm{~K}$ and $42 \mathrm{MPa}$ was approximately $0.1 \mathrm{~h}^{-1}$, which is rather high and on the same order as that for Karashima's data (Karashima et al., 1971) presented in Figure 3. Under these conditions, Fe-4Mo alloy needs approximately 4 times larger stress to attain the same strain rate as pure iron; the sub-grain size of $\mathrm{Fe}-4 \mathrm{Mo}$ alloy is rather small and the dislocation density is considerably higher, i.e., approximately 0.7 and 7.3 times those of pure iron, respectively. These findings indicate that the proportional coefficients in Equations 1 and 2 are not universal and are strongly affected by the chemical composition.

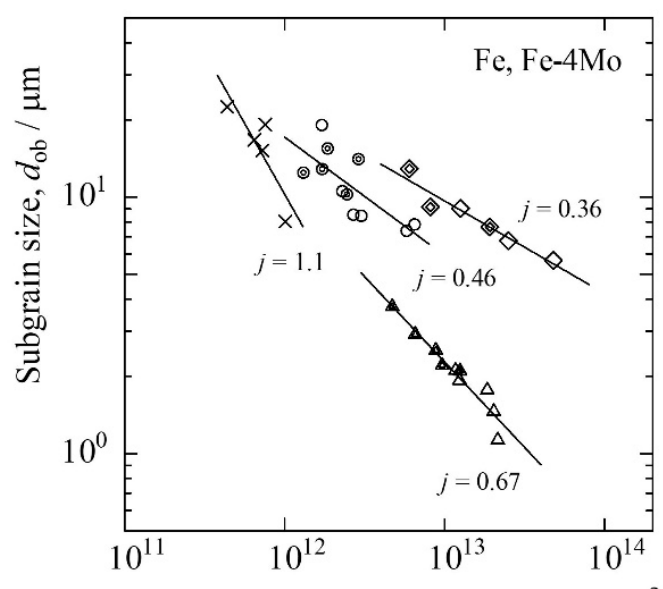

Dislocation density inside subgrain, $\rho_{\mathrm{ob}} / \mathrm{m}^{-2}$

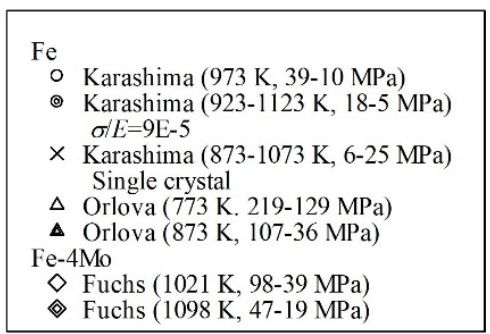

Figure 3. Correlation between $d_{\mathrm{ob}}$ and $\rho_{\mathrm{ob}}$ inside sub-grains in steadily crept specimens of alpha Fe and $\mathrm{Fe}-$ 4Mo alloy. Regression lines are shown for the data from each study. The cross marks represent data obtained using single crystals

\subsection{Austenitic Stainless Steel}

Cuddy (1970) determined $d_{\mathrm{ob}}$ and $\rho_{\mathrm{ob}}$ of Type 304 stainless steel at $977 \mathrm{~K}$ under applied stresses of 91-172 $\mathrm{MPa}$ and at $1082 \mathrm{~K}$ under applied stresses of $54-127 \mathrm{MPa}$. He used specimens crept up to a strain of 0.15 because Type 304 does not undergo steady-state creep under this condition. The strain rates at $977 \mathrm{~K}$ are judged to be approximately $2 \mathrm{E}-2 \mathrm{~h}^{-1}$ from his report, which are rather low. The results are plotted in Figure 4 . With increasing stress, the sub-grain size tended to decrease and the dislocation density tended to increase; the effect of temperature is not clear. A foil thickness of $200 \mathrm{~nm}$ was used for the TEM observation; this thickness is thinner than Fujita's criteria (Fujita et al. 1967) (a minimum thickness of $0.7 \mu \mathrm{m}$ for $\rho_{\mathrm{ob}} \geq 1 \mathrm{E} 12 \mathrm{~m}^{-2}$ or $0.2 \mu \mathrm{m}$ for $\rho_{\mathrm{ob}} \geq$ $1 \mathrm{E} 13 \mathrm{~m}^{-2}$ ) because strong pinning elements are not contained in a face-centered cubic (FCC) metal such as Al alloy and Type 304 steel. Therefore, the dislocation density in the low density range, $\rho_{\mathrm{ob}} \leq 1 \mathrm{E} 13 \mathrm{~m}^{-2}$, for Cuddy's data may be unreliable. We obtained $j=0.28$ for all Cuddy's data neglecting the reliability problem.

Kassner et al. (1982) examined the microstructure of Type 304 steel steadily deformed at $1023 \mathrm{~K}$ under applied equivalent (tensile) stresses of 120-208 MPa (converted from torsional stresses). The strain rate at $208 \mathrm{MPa}$ was $1.8 \mathrm{~h}^{-1}$, which is high. The observed $d_{\mathrm{ob}}$ and $\rho_{\mathrm{ob}}$ values are plotted in Figure 4 . The sub-grain size decreased and the dislocation density increased with increasing stress, as predicted from Equations 1 and 2. A value of $j=$ 0.67 was obtained for these data. Although the foil thickness is unknown, the dislocation density data are considered reliable because the dislocation densities were rather high. 


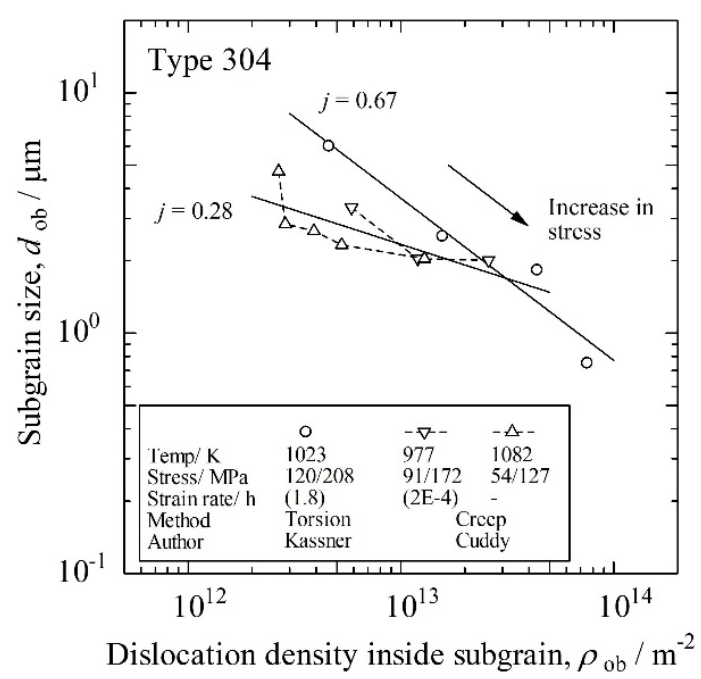

Figure 4. Correlation between $d_{\mathrm{ob}}$ and $\rho_{\mathrm{ob}}$ inside sub-grains in deformed specimens of Type 304 stainless steel.

Regression lines are shown for the creep and torsion data

Challenger \& Moteff (1973) determined $d_{\mathrm{ob}}$ and $\rho_{\mathrm{ob}}$ for Type 316 stainless steel deformed at $977-1089 \mathrm{~K}$ under applied stresses of 55-137 MPa, as shown in Figure 5. The specimens were crept up to a strain of 0.15 in steadystate creep. The strain rates ranged from $5.8 \mathrm{E}-4$ to $2.8 \mathrm{E}-3 \mathrm{~h}^{-1}$, which are low. In Figure 5, data obtained at the same temperature are connected using broken lines. The dislocation density at $1089 \mathrm{~K}$ may be unreliable according to Fujita's criteria (Fujita et al. 1967), as discussed above. The trends of the sub-grain size and dislocation density at each temperature are unclear; however, overall, the sub-grain size tended to decrease and the dislocation density tended to increase with increasing stress. A value of $j=0.55$ was obtained for all the data.

Michel et al. (1973) examined the substructure of Type 316 stainless steel deformed in slow tension between $294 \mathrm{~K}$ and $1089 \mathrm{~K}$. Sub-grains were developed at temperatures above $923 \mathrm{~K}$, and the observed $d_{\mathrm{ob}}$ and $\rho_{\mathrm{ob}}$ above $977 \mathrm{~K}$ are plotted in Figure 5. The strain rate was $9.7 \mathrm{E}-2 \mathrm{~h}^{-1}$, which is moderate. The foil thickness was $200 \mathrm{~nm}$, and the reliability of the observed dislocation density is considered reliable because it was sufficiently high, $\rho_{\mathrm{ob}} \geq 1 E 13 \mathrm{~m}^{-2}$. A value of $j=0.60$ was obtained for all the data. Comparison of the tension data with the creep data for similar subgrain size clearly reveals that the dislocation density increases with increasing strain rate or applied stress.

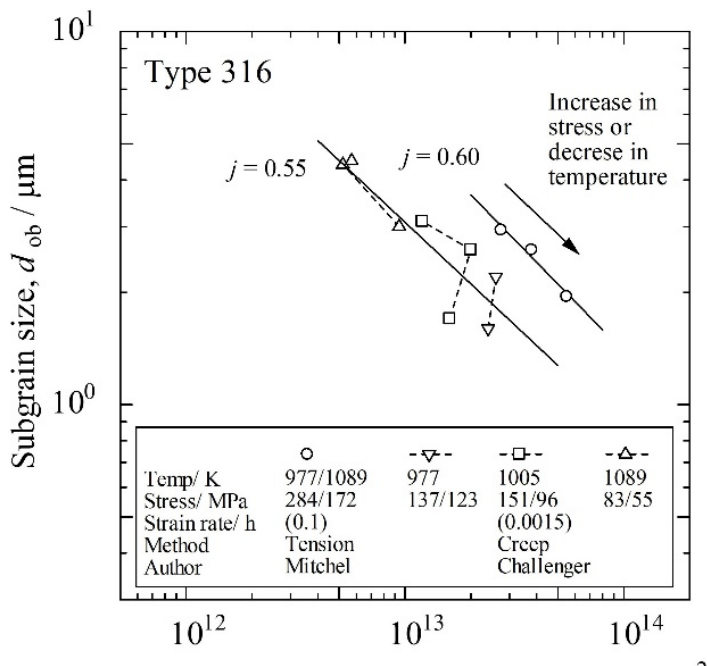

Dislocation density inside subgrain, $\rho_{\mathrm{ob}} / \mathrm{m}^{-2}$

Figure 5. Correlation between $d_{\mathrm{ob}}$ and $\rho_{\mathrm{ob}}$ inside sub-grains in deformed specimens of Type 316 stainless steel.

Regression lines are shown for the creep and tension data 


\subsection{High-Cr Martensitic Steel}

In creep of high-Cr martensitic steel, a MCR region is observed between transient creep and acceleration creep, the duration of which is rather long. Therefore, in this study, the MCR region is treated as steady-state creep. In addition, because lath boundaries are well developed in a tempered martensitic structure, they are also treated as sub-boundaries in this study. Although the foil thicknesses for TEM observations of martensitic steel are not reported in the literature, most dislocations are locked by dissolved carbon atoms in a BCC matrix according to Fujita et al. (1967), and the dislocation densities reported are all considered reliable because of the high density, BCC structure, and high carbon contents.

Sawada et al. (1997) performed creep tests on tempered martensitic steel, 9Cr1MoVNbN (Type 91), at $873 \mathrm{~K}$ under an applied stress of $177 \mathrm{MPa}$ and used TEM to determine the dislocation density inside the lath martensite in a creep-interrupted specimen strained up to near the MCR $(\varepsilon=0.02)$. The obtained $\rho_{\mathrm{ob}}$ value and width of lath martensite are plotted in Figure 6. The MCR was approximately $4 \mathrm{E}-4 \mathrm{~h}^{-1}$, which is small.

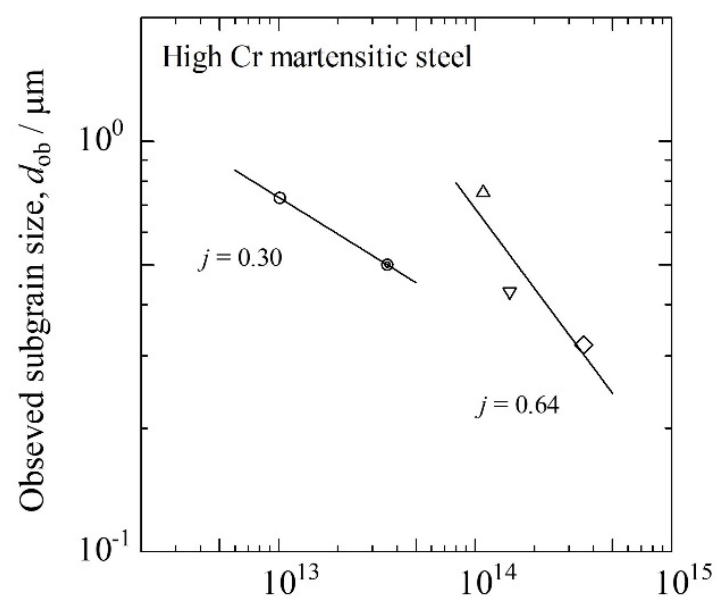

Dislocation density inside subgrains, $\rho_{\mathrm{ob}} / \mathrm{m}^{-2}$

\begin{tabular}{|llllll|}
\hline & $\odot$ & \multicolumn{1}{c|}{$\odot$} & \multicolumn{1}{c|}{$\Delta$} & \multicolumn{1}{c|}{} & $\diamond$ \\
Material & X20 & X20 & Type 91 & Co-P92 & P92 \\
Temp./K & 823 & 823 & 873 & 923 & 923 \\
Stress/MPa & 165 & 120 & 177 & 140 & 118 \\
Strain rate/h ${ }^{-1}$ & $2 \mathrm{E}-6$ & $9 \mathrm{E}-8$ & $4 \mathrm{E}-4$ & $2 \mathrm{E}-5$ & $4 \mathrm{E}-5$ \\
Time to MCR/h & 5010 & 30000 & 39 & 108 & 300 \\
Author & Straub & Bazazi & Sawada & Dudova & Dudko \\
& & & & & \\
\hline
\end{tabular}

Figure 6. Correlation between $d_{\mathrm{ob}}$ and $\rho_{\mathrm{ob}}$ inside sub-grains in deformed specimens of high-Cr martensitic steel. Regression lines are shown for X20 and other martensitic steel with high strength

Dudova et al. (2012) performed creep tests at $923 \mathrm{~K}$ under an applied stress of $140 \mathrm{MPa}$ on tempered martensitic steel 9Cr-2W-3Co-MoVNbNB (Co mod. Type P92), and the dislocation density inside the lath martensite/subgrain was determined using TEM in a creep-interrupted specimen strained up to near the MCR $(\varepsilon=0.01)$. The sub-grain size was determined using the linear intercept method. The results are plotted in Figure 6 . The MCR was approximately $2 \mathrm{E}-5 \mathrm{~h}^{-1}$, which is small.

Dudko et al. (2017) performed creep tests at $923 \mathrm{~K}$ and an applied stress of $118 \mathrm{MPa}$ on tempered martensitic steel $\mathrm{P} 92$, and the dislocation density inside the lath martensite and average sub-grain size were determined using TEM in a creep-interrupted specimen strained up to near MCR $(\varepsilon=0.01)$. The results are plotted in Figure 6 . The MCR was approximately $4 \mathrm{E}-5 \mathrm{~h}^{-1}$, which is small.

Straub et al. (1993) performed creep tests at $823 \mathrm{~K}$ under an applied stress of $165 \mathrm{MPa}$ on tempered martensitic steel X20, and the dislocation density inside the lath martensite/sub-grain was determined using TEM in a creepinterrupted specimen strained up to near the $\operatorname{MCR}(\varepsilon=0.02)$. The sub-grain size was determined using the linear intercept method. The results are plotted in Figure 6 . The MCR was approximately $2 \mathrm{E}-6 \mathrm{~h}^{-1}$, which is very small. 
Aghajani Bazazi (2009) performed long-term creep tests at $823 \mathrm{~K}$ under an applied stress of $120 \mathrm{MPa}$ on X20, and the dislocation density inside the sub-grains and the sub-grain size were determined using TEM for a creepinterrupted specimen strained up to near the MCR $(\varepsilon=0.008)$. The results are plotted in Figure 6 . The MCR was approximately $9 \mathrm{E}-8 \mathrm{~h}^{-1}$, which is extremely low.

No studies have been reported in the literature for high-Cr martensitic steel for which the stress and temperature dependence are reported in a single paper. However, to obtain $j$ values, the data in Figure 6 were classified into two groups: an X20 group and other martensitic steels with high strength, the $j$ values of which were 0.30 and 0.64 , respectively.

\section{Discussion}

\subsection{Relation between Observed Values and Equation 13}

In the previous section, the correlations between $d_{\mathrm{ob}}$ and $\rho_{\mathrm{ob}}$ determined from TEM analysis of $\mathrm{Al}, \mathrm{Cu}, \mathrm{Fe}, \mathrm{Fe}-$ Mo alloy, austenitic stainless steel, and high-Cr martensitic heat-resistant steel steadily crept at high temperatures were explained, and the $\rho_{\mathrm{ob}}$ values obtained using thin foils were shown to be consistent with those of bulk specimens. Figure 7 presents all of these data. The digital data and related parameters are shown in Table 1A in the appendix. The $j$ value for all the polycrystalline metal data excluding the single-crystal data for $\mathrm{Fe}$ is calculated to be 0.58 with a correlation coefficient of $r=81 \%$; in other words, the generally accepted relation, $d_{\mathrm{ob}} \propto \rho_{\mathrm{ob}}{ }^{-0.5}$ (Equation 3), is roughly reconfirmed. However, Figure 7 also indicates that although the slope of individual data groups, i.e., the $j$ value in Equation 3, ranges from 0.27 to 0.67 , depending on the type of metal and test conditions, On the other hand, when all the plotted data are fitted using Equation 13, we obtain the relation $d_{\mathrm{ob}}=3.08 \mathrm{E} 13 \rho_{\mathrm{ob}}{ }^{-1}$ with $r=86 \%$, and a value of $\eta=1.9$ is obtained from Equation 13 assuming $\varepsilon_{\mathrm{inc}}=$ $0.002, M=0.5$, and $b=0.25 \mathrm{~nm}$. Guide lines for Equation 13 for $\eta=0.1,1$, and 10 are also shown in Figure 7. These results do not indicate that Equation 13 is better than Equation 3, because both correlation coefficients obtained using equations 3 and 13 are not so high and in the eighties. The slope for pure iron (double square marks) is roughly 1 and that for others seems to be 0.5 . This indicates that the slope and the correlation coefficient are strongly affected by the characters of a statistical population. Moreover, Figure 7 indicates that all the data fall in a single and narrow band and data points tend to concentrate on a line $\eta=1$ when the data are tested at high temperatures and low stresses referring the explanation of each data shown in Figures 1 through 6 . This finding suggests that the relations in Figure 7 can be explained by some general rules.

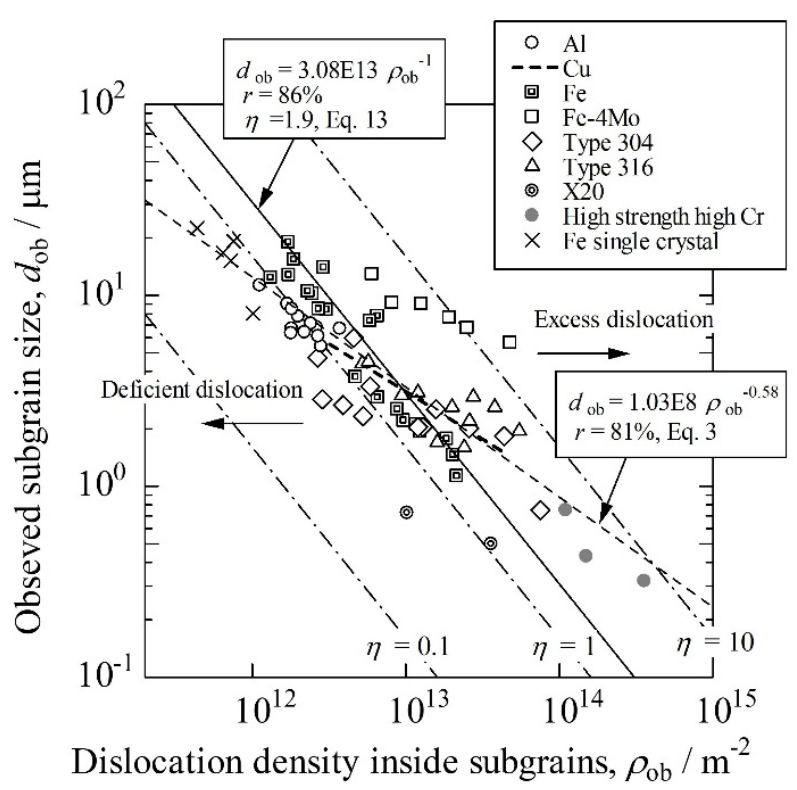

Figure 7. Correlation between $d_{\mathrm{ob}}$ and $\rho_{\mathrm{ob}}$ inside sub-grains in steadily crept specimens of pure $\mathrm{Al}$, pure $\mathrm{Cu}$, pure $\mathrm{Fe}, \mathrm{Fe}-4 \mathrm{Mo}$ alloy, austenitic stainless steel, X20, and high-Cr martensitic steel with high strength. The $\rho_{\mathrm{ob}}$ within a cell for $\mathrm{Cu}$ (bold broken line) was estimated using the method described in the text. Regression lines using Equations 3 and 13 are also shown. The relations between $\rho_{\mathrm{ob}}$ and $d_{\mathrm{ob}}$ estimated from Equation 13 are shown for $\eta=0.1,1$, and $10\left(\varepsilon_{\text {inc }}=0.002\right)$ as fine alternating long and short lines. The meanings of excess and deficient dislocations are provided in Section 4.2 
For Type 91 (Sawada et al., 1997) and P92 (Dudko et al., 2017) steels with tempered martensitic microstructure, the width of lath martensite is regarded to be $d_{\mathrm{ob}}$; therefore, the average $d_{\mathrm{ob}}$ may increase if the length of the lath martensite is considered. For example, if we consider lath martensite with an aspect ratio of 5.9 (Spiradek, Bauer, $\&$ Zeiler, 1994), the equivalent average $d_{\mathrm{ob}}$ with the same square section is $\sqrt{5.9} \approx 2.4$ times larger than the width of the lath martensite. Therefore, the two data points for Type 91 and P92 in Figure 6 (the two data points on the left side of the three data points for the high-strength high-Cr steels in Figure 7) shift upward by 2.4 times. However, the lath martensite structure is divided into some sub-grains perpendicular to the longitudinal axis of the lath martensite even after short-time creep (Sawada et al., 1997; Dudko et al., 2017); therefore, the aforementioned effective shape correction factor may not be so large. The sub-grain sizes for X20 and P92 were measured as the average size using the linear intercept method; therefore, there is no need for correction of these data.

The guide lines in Figure 7 were calculated for $b=0.25 \mathrm{~nm}$; however, the length of the Burgers vector for $\mathrm{Al}$ is at least $b=0.286 \mathrm{~nm}$ regardless of the temperature effect. Therefore, with strict calculations, the guide line for $\eta=1$ for Al shifts slightly downward.

The guide lines for $\eta=0.1,1$, and 10 in Figure 7 are given for $\varepsilon_{\text {inc }}=0.002$. This value is arbitrary and not theoretical. If $\varepsilon_{\text {inc }}$ increases to $\varepsilon_{\text {inc }}=0.0026$, the guide lines for $\eta=0.1,1$, and 10 in Figure 7 would shift upward according to Equation 13, and thus, the new virtual guide line for $\eta=1$ may approach the data plotted. After these corrections and considerations, we can confirm that most of the data plotted in Figure 7 are concentrated around a virtual guide line for $\eta=1$. That is, the validity of Equation 13 for the observed $d_{\mathrm{ob}}$ and $\rho_{\mathrm{ob}}$ in various materials is satisfactory and better than that of Equation 3.

\subsection{Metallurgical Meanings of $\eta$}

It was shown in the above sections that the sub-grain size, $d$, is inversely proportional to the dislocation density, $\rho$, swept out of a specimen (Equations 8 and 10 ), which are approximately related to $d_{\mathrm{ob}}$ and $\rho_{\mathrm{ob}}$, respectively, through Equation 13. However, Figures 1-7 also confirm that some data for a specified metal group are positioned away from the average guide line with $\eta=1.9$ under certain test conditions: the values of $\eta$ are high at higher stresses or lower temperatures or when the martensite structure is retained (for example, Type 91 vs. X20 in Figure 6) or for materials containing alloying elements such as Mo (Fe vs. Fe-4Mo in Figure 3 and Type 304 stainless steel vs. Type 316 stainless steel in Figures 4 and 5). Conversely, the values of $\eta$ are low for Fe single crystals (Figure 3), Type 304 stainless steel (Figure 4) at high temperatures, and for long-term tests for X20 (Figure 6). These circumstances should be explained.

First, at low temperatures and high stresses, the instantaneous strains are generally large (Sully, 1949; NIMS, 2007), and many dislocations are introduced directly after loading. These dislocations are annihilated and repeatedly rearranged with progressing creep strain; sub-grains or cells begin to form gradually, and finally, steadystate creep is achieved (Hasegawa et al., 1971; Sawada et al., 1997; Aghajani Bazazi, 2009). At this point, all the initially introduced dislocations are not completely annihilated or swept out of sub-grains, cells, or the specimen; instead, some of them remain in the sub-grains because of dislocation interactions. It is natural to assume that the number of remaining dislocations in the sub-grains is large when the number of dislocations initially introduced is large. Therefore, $\rho_{\mathrm{ob}}$ increases at lower temperatures and/or higher stresses, i.e., $\eta$ increases, and for many cases, the value of $j$ in Equation 3 for each data set, i.e., the regression coefficient between $\log d_{\mathrm{ob}}$ and $\log \rho_{\mathrm{ob}}$ apparently becomes less than unity, as observed in Figures 1-7.

After the shape correction of lath martensite for determining the average sub-grain size, as discussed in Sec. 4.1, the data for Type 91 and P92 steels in Figure 6 shifted substantially to the high- $\eta$ side compared with the other data. The test durations for the high-Cr martensitic steels were short, less than $300 \mathrm{~h}$ (Figure 6), compared with those for X20 steel, which initially had a similar martensitic structure but was tested for longer than $5010 \mathrm{~h}$. Therefore, the high $\rho_{\text {ob }}$ before loading due to the martensitic structure is thought to be retained for the three highCr martensitic steels, which leads to $\rho_{\mathrm{ob}}>\rho(\eta>1)$, because the recovery times for these high-strength steels were insufficient.

The observed dislocation densities for the Mo-containing materials, i.e., Fe-4Mo and Type 316 stainless steel, were higher than those for pure Fe and Type 304 stainless steel, respectively. Mo is one of the most popular strengthening elements for heat-resistant steel, which means that Mo can strongly delay recovery. Therefore, the initially introduced dislocations directly after loading remained inside the sub-grains for a longer time.

Similarly, the recovery corresponding to the data points shifted upward from the guide line for $\eta=1.9$ is judged to be delayed because of the low-temperature or short-duration tests or the alloying effect. 
However, sufficient recovery was achieved in X20 because of the long duration of the test and in Type 304 because of the absence of Mo and high temperature. In addition, because mobile dislocations are annihilated considerably, the $\eta$ values were less than unity or $\rho_{\mathrm{ob}}<\rho$. In single crystals of $\mathrm{Fe}$, the plastic constraint effect may be smaller than that in polycrystalline Fe; therefore, sub-grains grow easily and many dislocations are easily swept out of the sub-grains in single-crystal Fe. Moiseeva, Okrainets, \& Pishchak (1984) reported that the dislocation density inside a grain for crept pure Ni at $1173 \mathrm{~K}$ is roughly $1 \mathrm{E} 11 \mathrm{~m}^{-2}$ for a grain size of $1 \mu \mathrm{m}$ (based on TEM observations); however, the validity of these data cannot be accepted unconditionally because only one data point was presented and the foil thickness was not reported. In these specimens, the observed dislocation density was much smaller than the dislocation density necessary for creep, $\rho_{\mathrm{ob}}<\rho$. In these cases, the dislocation density inside a sub-grain or grain was low compared with that necessary for creep; therefore, the rapid multiplication of dislocations should necessarily occur.

Both Figure 7 and the above explanations clearly indicate that $\rho_{\mathrm{ob}}$ is large for lower temperatures and/or higher stresses, for a martensitic structure with insufficient recovery, or when strengthening elements such as Mo are contained, and thus, the values of $\eta$ are large. In this sense, the $\eta>1$ region is considered to be that of excess dislocations, whereas the $\eta<1$ region is considered to be that of deficient dislocations. That is, the metallurgical meaning of $\eta$ is a parameter representing excess or deficient dislocations.

\subsection{Movement of Dislocations}

If $\eta=1$ for each data point, the relation $\rho_{\mathrm{ob}}=\rho$ is obtained according to Equation 11. The dislocations making up $\rho$ are mobile and swept-out dislocations; however, this relation does not mean that all observed dislocations inside sub-grains are mobile because $\rho_{\mathrm{ob}}$ and $\rho$ are mutually independent variables. The definition of an immobile dislocation is $L<b$, where $L$ is the plastically moving distance of a dislocation during the time interval $\Delta t$ or strain increment $\varepsilon_{\text {inc }}$. Because mobile dislocations with $L=d$ contribute to creep deformation, for high values of $\eta$, it is natural that dislocations with $L<d \approx d_{\mathrm{ob}}$ including immobile dislocations (the density of which corresponds to $\rho_{\mathrm{ob}}-\rho$ ) are regarded as excess dislocations. Here, it may be possible that two dislocation pairs are activated, dislocations with different sign are annihilated inside a sub-grain, and the total traveling distance of the coalesced dislocation pair reaches $d$, which also causes plastic deformation. It is possible that $\rho_{\text {ob }}$ only consists of mobile dislocations regardless of the value of $\eta$. In this case, multiplication is necessary for $\eta \ll 1$, and conversely, for $\eta \gg 1$, the moving distances of mobile dislocations are small compared with the sub-grain size, $L \ll d$, because the number of swept out dislocations is determined only by $\rho$ and not by $\rho_{\text {ob }}$. Moreover, if only immobile dislocations exist in a sub-grain besides for a limited number of Frank-Read sources, the dislocations necessary for creep are supplied by multiplication. In any case, such dislocation motions may hardly occur during steady-state creep because mutual dislocation interactions of mobile dislocations can frequently occur inside sub-grains, which may cause hardening, i.e., non-steady-state creep. These situations are beyond the scope of this study.

Therefore, when we consider the $\rho_{\mathrm{ob}}$ vs. $d_{\mathrm{ob}}$ data sets for steady-state creep presented in Figure 7, according to Equation 13, it is reasonable to infer that approximately half of $\rho_{\mathrm{ob}}$ is composed of dislocations necessary for creep deformation, i.e., mobile dislocations, and the rest of the dislocations are immobile dislocations on average because $\eta=1.9 \approx 2$. In other words, most of the dislocations for high-strength high-Cr martensitic steel, T91, $\mathrm{Co}-\mathrm{P} 92$, P92, Fe-4Mo, and Type 316 stainless steel with the high values of $\eta$ shown in Figure 7 are considered to be immobile.

Table 1. Calculated parameters for T91 steel crept near the MCR at $913 \mathrm{~K}$ under an applied stress of $98 \mathrm{MPa}$. The following parameters obtained by Hayakawa et al. (2003 and 2007) were used in the calculations: mobile dislocation density inside a sub-grain $\rho_{\mathrm{sbm}}=2.0 \mathrm{E} 10 \mathrm{~m}^{-2}$, mobility $B=1 \mathrm{E}-15 \mathrm{~ms}^{-1} \mathrm{~Pa}^{-1}$, effective stress ratio $\sigma_{\text {eff }} / \sigma=0.15$, and $\dot{\varepsilon}(\mathrm{MCR})=8.33 \mathrm{E}-9 \mathrm{~s}^{-1}$. The sub-grain size of $d=7.5 \mathrm{E}-7 \mathrm{~m}$ obtained by Sawada et al. (1997) was also used in the calculations

\begin{tabular}{lcc}
\hline Variables & Units & Results \\
\hline Velocity, $u=B \sigma_{\mathrm{eff}}$ & $\mathrm{ms}^{-1}$ & $1.47 \mathrm{E}-8$ \\
Time to trip through a sub-grain, $t_{\mathrm{sg}}=d_{\mathrm{ob}} / u$ & $\mathrm{~s}$ & 51 \\
$\Delta t=0.002 / \dot{\varepsilon}$ for a creep strain of 0.002 & $\mathrm{~s}$ & $2.40 \mathrm{E} 5$ \\
Repeating factor, $\Delta t / t_{\mathrm{sg}}$ & - & $4.70 \mathrm{E} 3$ \\
Experimentally obtained mobile dislocation density swept out of a sub-grain during steady state & $\mathrm{m}^{-2}$ & $9.41 \mathrm{E} 13$ \\
creep, $\rho_{\mathrm{sbm}}(\exp )=\rho_{\mathrm{sbm}} \cdot \Delta t / t_{\mathrm{sg}}$ & & $2.13 \mathrm{E} 13$ \\
Swept out dislocation density from a sub-grain, $\rho$ calculated from Equations 11 and 12 & $\mathrm{~m}^{-2}$ & - \\
Magnification factor, $\rho_{\mathrm{sbm}}(\exp ) / \rho$ & - & 4.41 \\
\hline
\end{tabular}


The observed dislocation densities near the MCR for high-Cr martensitic steels determined using TEM shown in Figure 6 are on the order of $1 \mathrm{E} 14 \mathrm{~m}^{-2}$ at least for the data provided by Sawada et al. (1997). Hayakawa et al. (2003) reported that the mobile dislocation density during creep at approximately $923 \mathrm{~K}$ for T91 steel determined using the SCT method ranges from $1 \mathrm{E} 10$ to $1 \mathrm{E} 12 \mathrm{~m}^{-2}$, which is approximately three orders of magnitude smaller than the typically observed dislocation densities at 873-923 K determined from TEM observation; however, the test conditions were not the same for Sawada's and Hayakawa's data. Here, we will verify their experimental results based on the considerations presented in this paper. Hayakawa et al. $(2003,2007)$ conducted stress change creep tests near the MCR of T91 steel at $913 \mathrm{~K}$ for stresses of less than $98 \mathrm{MPa}$, and the following analytical results were obtained: mobile dislocation density inside a sub-grain, $\rho_{\mathrm{sbm}}=2.0 \mathrm{E} 10 \mathrm{~m}^{-2}$; mobility of dislocation, $B=$ $1 \mathrm{E}-15 \mathrm{~ms}^{-1} \mathrm{~Pa}^{-1}$; effective stress ratio, $\sigma_{\text {eff }} / \sigma=0.15$, where $\sigma_{\text {eff }}$ is the effective stress applied to mobile dislocations; $\sigma_{\text {eff }}=\sigma-\sigma_{\mathrm{i}}$, where $\sigma_{\mathrm{i}}$ is the internal stress; and MCR, $\dot{\varepsilon}=8.33 \mathrm{E}-9 \mathrm{~s}^{-1}$. The following variables were calculated in the current work using these parameters in addition to the sub-grain size $d_{\mathrm{ob}}=7.5 \mathrm{E}-$ $7 \mathrm{~m}$ obtained by Sawada et al.(1997). Namely, the dislocation velocity, $\mathrm{u}=B \sigma_{\text {eff }}$, is $1.47 \mathrm{E}-8 \mathrm{~ms}^{-1}$; the time to travel through a sub-grain, $t_{\mathrm{sg}}=d_{\mathrm{ob}} / u$, is $51 \mathrm{~s}$; the time interval $\Delta t=\varepsilon_{\text {inc }} / \dot{\varepsilon}$ for $\varepsilon_{\text {inc }}=0.002$ is $2.40 \mathrm{E} 5 \mathrm{~s}$; and the repeating factor, $\Delta t / t_{\mathrm{sg}}$, is 4700 . Finally, the experimentally determined swept out dislocation density from a sub-grain for $\Delta t, \rho_{\mathrm{sbm}}(\exp )=\rho_{\mathrm{sbm}} \Delta t / t_{\mathrm{sg}}$, is calculated to be $9.41 \mathrm{E} 13 \mathrm{~m}^{-2}$ using Equations 11 and 13 . These results are summarized in Table I. The theoretical value of $\rho$ for a given value of $d$ and $\eta=1$ is calculated to be $2.13 \mathrm{E} 13 \mathrm{~m}^{-2}$ using Equation 13, and the magnification factor, $\rho_{\mathrm{sbm}}(\exp ) / \rho$, is 4.41 . These findings indicate that the value of $\rho_{\text {sbm }}(\exp )$ is overestimated or that mobile dislocations only move occasionally with a probability of $1 / 4.41 \approx 23 \%$. This result does not mean that all the dislocations move or stop simultaneously but that they move randomly and with frequent stops. Therefore, the velocity of each dislocation possibly increases by an average of 4.41 times the velocity listed in Table 1, such that dislocation motion can be more easily and directly observable using TEM. Conversely, these findings suggest that if the mobile dislocations move continuously inside sub-grains, a considerable amount of dislocations should be trapped by other dislocations or other defects inside sub-grains; however, this phenomenon would cause work hardening, and steady-state creep would not hold. These situations support the idea that most of the dislocations in the range of excess dislocation are immobile dislocations.

\subsection{The Way of Advances}

Steel products composed of high-Cr martensitic steel with high strength are widely used for power plants, which has contributed to reducing greenhouse gas emissions from fossil power plants (Masuyama, 2001). However, the unexpected decrease in strength of these steels after long-term service remains a critical issue (Kushima, Kushima, Yagi, \& Tanaka, 1991; Abe, 2006; Tamura, 2015), and the maximum allowable tensile stresses for these highstrength steels has been revised (Masuyama, 2007). However, sufficient rupture data at 100,000 $\mathrm{h}$ for these steels needed to determine the allowable stresses have not yet been obtained. One countermeasure for this problem is to predict the residual lives of the particular components in each power plant over a short time (Masuyama, 2013; Masuyama, Tokunaga, Shimohara, Yamamoto, \& Hirano, 2009; Kimura, 2009; Maruyama, Nakamura, \& Yoshimi, 2016). Therefore, variations in both the dislocation density (Straub et al., 1993; Spiradek et al., 1994; Sawada et al., 1997; Kadoya \& Shimizu, 2000; Ennis, 2002; Hayakawa et al. 2003; Kassner, 2004; Aghajani Bazazi, 2009; Dudova et al. 2012; Dudko et al., 2017) and sub-grain size (Sawada, 1997; Kadoya \& Shimizu, 2000 and 2002; Blum \& Gotz, 1999; Ennis \& Czyrska-Filemonowicz, 2002; Qin, Gotz, \& Blum, 2003; Aghajani Bazazi, 2009; Aghajani et al., 2009; Dudova et al., 2012; Dudko et al., 2017) during creep have been studied individually as indicators for material degradation together with the changes in hardness, microstructure, and mechanical properties (Kushima et al., 1991; Sawada et al, 1997; Masuyama et al., 2009; Kabadwal, Tamura, Shinozuka, \& Esaka, 2010; Fedoseeva et al., 2016). The residual lives of the in-service components have been estimated based on these reported changes, and damaged parts are scheduled to be replaced by new ones based on these findings.

It is well known that the sub-grain size increases and the dislocation density decreases during service and that both variables can be investigated using small samples within a shorter time than that needed for creep tests. However, there are no threshold values below the specified dislocation density or above the specified sub-grain size for which the components would fracture rapidly (such as those provided for allowable stresses); therefore, more quantitative indexes concerning $\rho_{\mathrm{ob}}$ and $d_{\mathrm{ob}}$ are expected. According to Equation 13, the product of $\rho_{\mathrm{ob}}$ and $d_{\mathrm{ob}}$ can be summarized by only one parameter, $\eta$, which is independent of other parameters such as stress, temperature, and chemical composition. Moreover, $\eta$ represents the state of excess dislocations (possibly immobile ones) inside a sub-grain, and the lower limit is $\eta \approx 1$, as shown in Figure 7 , which is the value for pure metals. 
The above discussion is based on data obtained during steady-state creep. Therefore, if the value of $\eta$ is used as an index for the degradation of martensitic steel components of power plants, the variations in $\eta$ during the entire creep life from the initial stages to rupture should be systematically investigated. Based on these analyses, the values of $\eta$ could provide an effective index to evaluate the soundness of in-service components when combined with well-established properties such as hardness, which contribute to residual life prediction technology for power-plant components.

\section{Conclusions}

1) The size of an observed sub-grain formed during steady-state creep, $d_{\mathrm{ob}}$, can be formulated using Equations 11 and 12 and is inversely proportional to the dislocation density, $\rho$, which is the number of dislocations swept out of the sub-grain divided by the cross-sectional area of the sub-grain.

2) The dislocation density, $\rho_{\mathrm{ob}}$, inside a sub-grain during steady-state creep of cubic metals determined using TEM can be related to $\rho$ using the relation $\rho_{\mathrm{ob}}=\eta \rho$, where $\eta$ is an index of the state of excess (possibly immobile) dislocations inside a sub-grain. At low temperatures and/or high stresses for Mo-containing alloys and martensitic steel, we confirm the relation $\eta>1$; however, at high temperatures and low stresses for pure metals, $\eta \approx 1$.

3) The above theoretical relation of $d_{\mathrm{ob}} \propto \rho^{-1}$ or $d_{\mathrm{ob}} \propto \eta \cdot \rho_{\mathrm{ob}}{ }^{-1}$ essentially differs from the empirical relation $d_{\mathrm{ob}} \propto \rho_{\mathrm{ob}}{ }^{-j}$, where $j \approx 0.3-1.0$.

\section{Table of Symbols}

$\begin{array}{ll}\alpha & \text { Constraint parameter in Equation } 6 \\ \varepsilon_{\mathrm{inc}} & \text { Observed creep strain increment within } \Delta t \\ \varepsilon_{\mathrm{v}} & \text { Plastic strain in a virtual domain within } \Delta t \\ \eta & \text { Coefficient of Equation } 11 \\ \rho & \text { Dislocation density calculated from dislocations swept out of a sub-grain within } \Delta t \\ \rho_{\mathrm{m}} & \text { Mobile dislocation density inside a sub-grain } \\ \rho_{\mathrm{ob}} & \text { Observed dislocation density inside a sub-grain } \\ \rho_{\mathrm{sb}} & \text { Dislocation density actually existing inside a sub-grain during steady-state creep } \\ \rho_{\mathrm{sbm}} & \text { Mobile dislocation density actually existing inside a sub-grain during steady-state creep } \\ \rho_{\mathrm{sbs}} & \text { Sessile dislocation density actually existing inside a sub-grain during steady-state creep } \\ b & \text { Length of Burgers vector } \\ d & \text { Sub-grain size during steady-state creep } \\ d_{\mathrm{m}} & \text { Size of a virtual domain } \\ d_{\mathrm{ob}} & \text { Observed sub-grain size } \\ G & \text { Shear modulus } \\ L & \text { Plastically moving distance of a dislocation within } \Delta t \\ M & \text { Conversion factor from shear strain to tensile strain } \\ n_{0} & \text { Number of dislocations swept out of a virtual domain within } \Delta t \\ \Delta t & \text { Arbitrary time interval during steady-state creep } \\ \mathrm{R} & \end{array}$

\section{References}

Abe, F. (2006). Present status of advanced high-Cr ferritic heat resistant steels for ultra supercritical power plants. Ferrum, 11, 197-207. Retrieved from https://www.isij.or.jp/?lang=english

Abe, K., Yoshinaga, H., \& Morozumi, S. (1976). A method of discerning frictional stress and internal stress by the stress relaxation test. Journal of Japan Institute of Metals, 40, 393-399. Retrieved from http://jim.or.jp/ PUBS/thesis_j/j_index.html

Aghajani Bazazi, A. (2009). Evolution of Microstructure during Long-term Creep of a Tempered Martensite Ferrite Steel, Dissertation Doktor-Ingenieur of Ruhr-Universitaet, Bochum, Germany. http://wwwbrs.ub.ruhr-uni-bochum.de/netahtml/HSS/Diss/AghajaniBazaziAli/diss.pdf 
Aghajani, A., Somsem, Ch., \& Eggeler, E. (2009). On the effect of long-term creep on the microstructure of a 12\% chromium tempered martensite ferritic steel. Acta Materialia, 57, 5093-5106. https://doi.org/10.1016/ j.actamat.2009.07.010

Ashby, M. F. (1970). The deformation of plasticity non-homogeneous materials. Phiosophical Magazine, 21, 399424. https://doi.org/10.1080/14786437008238426

Blum, W., \& Straub, S. (1991). Subgrain growth during creep of a tempered martensitic $12 \%$ Cr-steel. Steel Research, 62, 72-74. https://doi.org/10.1002/srin.199101253

Blum, W., \& Gotz, G. (1999). Evolution of dislocation structure in martensitic steels: the subgrain size as a sensor for creep strain and residual creep life. Steel Research, 70, 274-278. https://doi.org/10.1002/srin.199905639

Challenger, K. D., \& Moteff, J. (1973). Quantitative characterization of the substructure of AISI 316 stainless steel resulting from creep. Metallurgical Transactions, 4, 749-755. https://doi.org/10.1007/BF02643084

Chen, B., Flewitt, P. E. J., Cocks, A. C. F., \& Smith, D. J. (2015). A review of the changes of internal state related to high temperature creep of polycrystalline metals and alloys. International materials Reviews, 60, 1-28. https://doi.org/10.1179/1743280414Y.0000000041

Cottrell, A. H. (1964). Theory of Crystal Dislocations, pp. 6-7. New York, NY: Gordon and Breach. Retrieved from https://www.amazon.com/Theory-Crystal-Dislocations-H-Cottrell/dp/0677001754

Cuddy, L. J. (1970). Internal stresses and structures developed during creep. Metallurgical Transactions, 1, 395401. https://doi.org/10.1007/BF02811548

Dudko, V., Belyyakov, A., \& Kaibyshev, R. (2017). Evolution of lath substructure and internal stresses in a 9\% Cr steel during creep. ISIJ International, 57, 540-549. https://doi.org/10.2355/isijinternational.ISIJINT-2016334

Dudova, N., Plotnikova, A., Molodov, D., Belyakov, A., \& Kaibyshev, R. (2012). Structural changes of tempered martensitic $9 \% \mathrm{Cr}-2 \% \mathrm{~W}-3 \% \mathrm{Co}$ steel during creep at $650^{\circ} \mathrm{C}$. Materials Science and Engineering A, 534, 632639. http://dspace.bsu.edu.ru/bitstream/123456789/4756/3/Dudova_N_Structural.pdf

Ennis, P. J., \& Czyrska-Filemonowicz, A. (2002). Recent advances in creep resistant steels for power plant applications. OMMI, 1, 1-28. https://doi.org/10.1007/BF02706455

Evangelista, E., Guardamagna, C., Kloc, L., Rosen, A., \& Spigrarelli, S. (1995a). The role of cold working in the creep deformation of $\mathrm{Nb}$ stabilized stainless steel I. Creep results and microstructural evolution. High Temperature Materials and Processes, 14, 151-161. https://doi.org/10.1515/HTMP.1995.14.3.151

Evangelista, E., Guardamagna, C., Kloc, L., Rosen, A., \& Spigrarelli, S. (1995b). The role of cold working in the creep deformation of $\mathrm{Nb}$ stabilized stainless steel II. Creep equations. High Temperature Materials and Processes, 14, 163-171. https://doi.org/10.1515/HTMP.1995.14.3.163

Fedoseeva, A., Dudova, N., \& Kaibyshev, R. (2016). Creep strength breakdown and microstructure evolution in a 3\%Co modified P92 steel. Materials Science \& Engineering A, 654, 1-12. https://doi.org/10.1016/j.msea.2015.12.027

Frost, H. J., \& Ashby, M. F. (1982). Deformation-Mechanism Maps, Oxford: Pergamon Press. Retrieved from https://www.amazon.co.jp/Deformation-Mechanism-Maps-Plasticity-Metals-Ceramics/dp/0080293387

Fuchs, A., \& Ilschner, B. (1969). An analysis of the creep behaviour of iron-molybdenum solid solutions. Acta Metallurgica, 17, 701-710. https://doi.org/10.1016/0001-6160(69)90076-5

Fujita, H., Kawasaki, Y., Furubayashi, E., Kajiwara, S., \& Taoka, T. (1967). Metallurgical investigation with a $500 \mathrm{kV}$ electron microscope. Japanese Journal of Applied Physics, 6, 214-230. Retrieved from http://iopscience.iop.org/article/10.1143/JJAP.6.214/pdf

Hasegawa, T., Karashima, S., \& Hasegawa, R. (1971). Substructue formation and nonuniformity in strain during high temperature creep of copper single crystals. Metallurgical Transactions, 2, 1449-1455. https://doi.org/10. 1007/BF02913374

Hayakawa, H., Terada, D., Yoshida, H., Nakashima, H., \& Goto, Y. (2003). Evaluation of mobile dislocation density of modified 9Cr-1Mo steel by stress change test. Tetsu-to-Hagane, 89, 1076-1081. https://doi.org/10.2355/tetsutohagane1955.89.10_1076

Hayakawa, H., Nakashima, S., Kusumoto, J., Kanaya, A., Terada, D., Yoshida, F., \& Nakashima, H. (2007). Evaluation of creep deformation mechanism of heat resistant steel by stress change test in Proc. CREEP 8 
Eighth International Conference on Creep and fatigue at Elevated Temperatures July 22-26 San Antonio TX CREEP 200 -26501 (pp.1-10). Warrendale, PA: ASME. http://dx.doi.org/10.1115/CREEP2007-26501

Holt, D. L. (1970). Dislocation cell formation in metals. Journal of Applied Physics, 41, 3197-3201. https://doi.org/10.1063/1.1659399

Jones, B. L., \& Sellars, C. M. (1970). The creep of copper, copper-10 at.-\% nickel, and copper-10 at-\% Gold. Metal Science Journal, 4, 96-102. https://doi.org/10.1063/1.1659399

Hull, D., \& Bacon, D. J. (2011). Introduction to Dislocations, pp. 81-83. Amsterdam: Elsevier. https://doi.org/10.1016/C2009-0-64358-0

Kabadwal, A., Tamura, M., Shinozuka, K., \& Esaka, H. (2010). Recovery and precipitate analysis of 9 pct Cr-1 pct MoVNb steel during creep. Metallurgical and Materials Transactions A, 41A, 364-379. https://doi.org/ 10.1007/s11661-009-0094-9

Kadoya, Y., \& Shimizu, E. (2000). Effect of solute Mo and W on transient creep deformation of high-Cr ferritic steels. Tetsu-to-Hagane, 86, 189-95. https://doi.org/10.2355/tetsutohagane1955.86.9_617

Kadoya, Y., Dyson, B. F., \& McLean, M. (2002). Microstructural stability during creep of Mo- or W-bearing 12Cr steel. Metallurgical Materials Transaction A, 33A, 2549-2557. https://doi.org/10.1007/s11661-002-0375-z

Kadoya, Y., \& Shimizu, E. (2002). Effect of Co on creep deformation and precipitation behavior of high-Cr ferritic steel. Tetsu-to-Hagane, 88, 539-546. https://doi.org/10.2355/tetsutohagane1955.88.9_539

Karashima, S., Iikubo, T. Watanabe, T., \& Oikawa, H. (1971). Transmission electron microscopy of substructures developed during high-temperature creep in alpha-iron. Transactions of JIM, 12, 369-374. https://doi.org/ 10.2320/matertrans1960.12.369

Karashima, S., Iikubo, T., \& Oikawa, H. (1972). On the high-temperature creep behaviour and substructure in alpha-iron single crystals. Transactions of JIM, 13, 176-181. https://doi.org/10.2320/matertrans1960.13.176

Kassner, M. E., Miller, A. K., \& Sherby, O. D. (1982). The separate roles of subgrains and frost dislocations in the isotropic hardening of type 304 stainless steel. Metallurgical transactions A, 13A, 1977-1985. https://doi.org/10.1007/BF02645943

Kassner, M. E. (2004). Taylor hardening in five-power-law creep of metals and class M alloys. Acta. Materialia, 52, 1-9. https://doi.org/10.1016/j.actamat.2003.08.019

Kassner, M. E. (2009). Fundamentals of Creep in Metals and Alloys (pp. 28-37), Amsterdam: Elsevier. Retrieved from https://www.elsevier.com/books/fundamentals-of-creep-in-metals-and-alloys/kassner/978-0-08-047561-5

Kimura, K., Kushima, H., Yagi, K., \& Tanaka, C. (1991). Fundamental properties of long-term creep strength for ferritic heat resistant steels. Tetsu-to-Hagane, 77, 667-674. https://doi.org/10.2355/tetsutohagane1955.77.5_667

Kimura, K. (2009). Creep life prediction of creep resistant steels. Journal of Japan Institute of Metals, 73, 323333. Retrieved from https://inis.iaea.org/search/search.aspx?orig_q=RN:41014936

Kratochvil, J., \& Sedlacek, R. (2004). Energetic approach to subgrain formation. Materials Science and Engineering A, 387-389, 67-71. https://doi.org/10.1016/j.msea.2004.01.069

Maruyama, K., Nakamura, J., \& Yoshimi, K. (2016). Assessment of long-term creep rupture strength of T 91 steel by multiregion rupture data analysis. Transactions of the ASME Journal of Pressure Vessel Technology, 138, pp. 031407 (1-9). doi: 10.1115/1.4032647, Retrieved from http://pressurevesseltech.asmedigitalcollection. asme.org/article.aspx?articleid $=2488083$

Masuyama, F. (2001). History of power plants and progress in heat resistant steels. ISIJ International, 41, 612625. https://doi.org/10.2355/isijinternational.41.612

Masuyama, F. (2007). Creep rupture life and design factors for high-strength ferritic steels. International Journal of Pressure Vessels and Piping, 84, 53-61. https://doi.org/10.1016/j.ijpvp.2006.09.006

Masuyama, F., Tokunaga, T., Shimohara, N., Yamamoto, T., \& Hirano, M. (2009). Comprehensive approach to creep life assessment of martensitic heat resitant steels. OMMI, 6, 1-14. http://www.ommi.co.uk/PDF/ Articles/191.pdf

Masuyama, F. (2013). Advances in creep damage/life assessment technology for creep strength enhanced ferritic steels. Procedia Engineering, 55, 591-598. https://ac.els-cdn.com/S1877705813006541/1-s2.0-S187770581 3006541-main.pdf?_tid=6627c0b4-6892-4bef-b4e5-5bbe5193882e\&acdnat=1530912474_057a8cbce2b24952 d6b29112400f9c5a 
Michel, D. J., Moteff, J., \& Lovell, A. J. (1973). Substructure of type 316 stainless steel deformed in slow tension at temperatures $21^{\circ}$ and $816^{\circ} \mathrm{C}$. Acta Metallurgica, 21, 1269-1277. https://doi.org/10.1016/0001-6160(73) 90168-5

Moiseeva, I. V., Okrainets, P. N., \& Pishchak, V. K. (1984). Dislocation density changes in nickel under creep. Ukrainskij Fizicheskij-Zhurnal, 29, 274-279. Retrieved from https://inis.iaea.org/search/search.aspx?orig_q $=\mathrm{RN}: 16037795$

Mukherjee, A. K. (1975). High-temperature creep. In R. J. Arsenault (ed.), Plastic Deformation of Materials (pp. 163-224). New York: Academic Press. Retrieved from https://www.elsevier.com/books/plastic-deformationof-materials/arsenault/978-0-12-341806-7

Norman Ahlquist, C., \& Nix, W. D. (1969). A technique for measuring mean internal stress during high temperature creep. Scripta Metallurgica, 3, 679-682. https://doi.org/10.1016/0036-9748(69)90076-3

NIMS (2007): NIMS Creep Data Sheet Atlas of Creep Deformation Property No. D-1, Creep Deformation Properties of $9 \mathrm{Cr} 1 \mathrm{Mo}-\mathrm{V}-\mathrm{Nb}$ Steel Tubes for Boilers and Heat Exchangers (ASME SA-213/SA-213M Grade T91) and 9Cr-1Mo-V-Nb Steel Plate for Boilers and Pressure Vessels (ASME SA-387/SA-387M Grade 91), Tsukuba, Japan. Retrieved from http://www.nims.go.jp/nims/english/creep_1st._e.htm

Orlova, A., Tobolova, Z., \& Cadek, J. (1972). Internal stress and dislocation structure of aluminium in hightemperature creep. Philosophical Magazine, 26, 1263-1274. https://doi.org/10.1080/14786437208220340

Orlova, A., \& Cadek, J. (1973). Some substructural aspects of high-temperature creep in metals. Philosophical Magazine, 28, 891-899. https://doi.org/10.1080/14786437308220990

Orlova, A., Bursik, J., Kucharova, K., \& Sklenicka, V. (1998). Microstructural development during high temperature creep of $9 \% \mathrm{Cr}$ steel. Materials Science and Engineering, A245, 39-48. https://doi.org/10.1016/S0921-5093(97)00708-9

Orowan, E. (1940). Problems of plastic gliding. Proceedings of the Physical Society, 52, 8-22. https://dx.doi.org/10.1088/0959-5309/52/1/303

Otte, H. M., \& Hren, J. J. (1966). The observation of crystalline imperfections and their role in plastic deformation. Experimental Mechanics, 6, 177-193. https://doi.org/10.1007/BF02326148

Qin, Y., Gotz, G., \& Blum, W. (2003). Subgrain structure during annealing and creep of the cast marternsitic Crsteel G-X12CrMoWVNbN 10-1-1. Materials Science and Engineering A, 341, 211-215. https://doi.org/10.1016/S0921-5093(02)00215-0

Raj, S. V., \& Pharr, G. M. (1986). A compilation and analysis of data for the stress dependence of the subgrain. Materials Science and Engineering, 81, 217-237. https://doi.org/10.1016/0025-5416(86)90265-X

Sawada, K., Maruyama, K., Komine, R., \& Nagae, Y. (1997). Microstruictural changes during creep and life

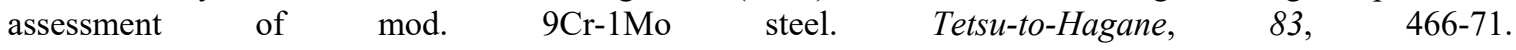
https://doi.org/10.2355/tetsutohagane1955.83.7_466

Sedlacek, R., Blum, W., Kratochvil, J., \& Forest, S. (2002). Subgrain formation during deformation: Physical origin and consequences. Metallurgical and Materials Transactions. A, 33A, 319-27. https://doi.org/10.1007/s11661-002-0093-6

Solomon, A. A. (1969). New techniques and apparatus for examining the elevated temperature deformation of metals. The Review of Scientific Instruments, 40, 1025-1028. https://doi.org/10.1063/1.1684142

Spiradek, K., Bauer, R., \& Zeiler, G. (1994). Microstructural changes during the creep deformation of $9 \% \mathrm{Cr}$-steel. In D. Coutsouradis et al. (eds.), Materials for Advanced Power Engineering Part I. pp. 251-62. The Netherlands: Kluwer Academic Publisher. https://books.google.co.jp/books?id=wF3RECzsNWAC\&pg $=$ PA251\&lpg=PA251\&dq=Spiradek+Materials + for + Advanced + Power+Engineering + Part $+\mathrm{I}+$ Microstructural + changes+during + the + creep+deformation + of $+9 \% 25 \mathrm{Cr}$-steel\&source=bl\&ots=zuXJbgXlp_\&sig=cczyBX_DGDPUxsqKQyyOXFOFEQ\&hl=ja\&sa=X\&ved=0ahUKEwiPz935vIvcAhUSC6YKHQatCa0Q6AEIN TÁD\#v $=$ onepage $\& \mathrm{q}=$ Spiradek $\% 20$ Materials $\% 20$ for $\% 20$ Advanced $\% 20$ Power $\% 20$ Engineering $\% 20$ Part $\% 20 \mathrm{I} \% 20 \mathrm{Mic}$ rostructural $\% 20$ changes $\% 20$ during $\% 20$ the $\% 20 \mathrm{creep} \% 20$ deformation $\% 20$ of $\% 209 \% 25 \mathrm{Cr}$-steel $\& \mathrm{f}=$ false

Staker, M. R., \& Holt, D. L. (1972). The dislocation cell size and dislocation density in copper deformed at temperatures between 25 and $700^{\circ} \mathrm{C}$. Acta Metallurgica, 20, 569-579. https://doi.org/10.1016/00016160(72)90012-0 
Straub, S., Meter, M., Ostermann, J., \& Blum, W. (1993). Entwicklung der mikrostruktur und der festigkeit des stahles X $20 \mathrm{CrMoV} 121$ bet $823 \mathrm{~K}$ waehend zeitstandbeanspruchung und gluehung. VGB Kraftwerkstechnik, 73, 646-653. Retrieved from https://www.vgb.org/jahresinhaltsverzeichnisse_d.html?dfid=35293

Sully, A. H. (1949). Metallic Creep and Creep Resistant Alloys, pp. 37-57. London: Butterworths Scientific Pub. https://www.amazon.com/Metallic-Creep-Resistant-Alloys/dp/B000QAD1IW

Takeuchi, S., \& Argon, A.S. (1976). Steady-state creep of single-phase crystalline matter at high temperature. Journal of Materials Science, 11, 1542-1566. https://doi.org/10.1007/BF00540888

Tamura, M. (2015). Method of estimating the long-term rupture strength of $11 \mathrm{Cr}-2 \mathrm{~W}-0.4 \mathrm{Mo}-1 \mathrm{Cu}-\mathrm{Nb}-\mathrm{V}$ steel. Metallurgical and Materials transactions A, 46, 1958-1972. https://doi.org/10.1007/s11661-015-2784-9

Tamura, M., \& Abe, F. (2015). Changes in estimated dislocation density during creep in martensitic heat-resistant steel. Journal of Materials Science Research, 4(4), 48-69. http://dx.doi.org/10.5539/jmsr.v4n4p48

Tamura, M. (2017). Verification of equation for evaluating dislocation density during steady-state creep of metals. Journal of Materials Science Research, 6(2), 20-62. https://doi.org/10.5539/jmsr.v6n2p20

Toma, K., Yoshinaga, H., \& Morizumi, S. (1975). The internal stress in high-temperature deformation of pure metals. Journal of Japan Institute of Metals, 39, 621-625. https://doi.org/10.2320/jinstmet1952.39.6_621

Toriumi, M. (1979). Relation between dislocation density and subgrain size of naturally deformed olivine in peridotites. Contributions to Mineralogy and Petrology, 68, 181-186. https://doi.org/10.1007/BF00371899

Wetter, T. S. (1986). The Variation of the Dislocation Density in Aluminum Deformed to Large Steady-state Creep Strains. Thesis of Naval Postgraduate School, Monterey, CA. Retrieved from http://www.dtic.mil/dtic/tr/ fulltext/u2/a167715.pdf

Yoshinaga, H., Toma, K., \& Morozumi, S. (1974). The high-temperature deformation mechanism in Al-Mg alloys and the internal stress. Journal of Japan Institute of Metals, 38, 826-834. https://doi.org/10.2320/matertrans 1960.17.559

\section{Appendix}

Table A1. Digital data of dislocation density and sub-grain size for Figure 7. Most of the data are read from the graphs in the original papers cited in the text. The excess dislocation parameters, $\eta$, are calculated using Equation 13 assuming $M=0.5$ and $b=2.5 \mathrm{E}-10 \mathrm{~m}$. The test temperatures, stresses, and strain rates are also given in the table for convenience

\begin{tabular}{|c|c|c|c|c|c|c|c|c|}
\hline Material & $\begin{array}{l}\text { Temperature/ } \\
\mathrm{K}\end{array}$ & $\begin{array}{l}\text { Sub-grain } \\
\text { size/ }\end{array}$ & $\mathrm{m}$ & $\begin{array}{l}\text { Dislocation } \\
\text { density } / \mathrm{m}^{-2}\end{array}$ & $\begin{array}{l}\text { Stress/ } \\
\mathrm{MPa}\end{array}$ & $\begin{array}{l}\text { Strain rate/ } \\
\mathrm{h}^{-1}\end{array}$ & $\begin{array}{l}\text { Excess } \\
\text { dislocation } \\
\text { parameter, } \eta\end{array}$ & Author(s) \\
\hline \multirow{12}{*}{$\mathrm{Al}$} & 644 & $1.13 \mathrm{E}-05$ & & $1.12 \mathrm{E}+12$ & 6.41 & $1.81 \mathrm{E}+00$ & 0.79 & Wetter, (1986) \\
\hline & 573 & $9.01 \mathrm{E}-06$ & & $1.69 \mathrm{E}+12$ & 3.9 & & 0.95 & \multirow{11}{*}{ Orlova et al. (1972) } \\
\hline & 573 & 7.75E-06 & & $2.00 \mathrm{E}+12$ & 4.9 & & 0.97 & \\
\hline & 573 & $8.48 \mathrm{E}-06$ & & $1.82 \mathrm{E}+12$ & 7.4 & & 0.96 & \\
\hline & 573 & $6.82 \mathrm{E}-06$ & & $2.62 \mathrm{E}+12$ & 9.8 & & 1.12 & \\
\hline & 573 & 7.12E-06 & & $2.41 \mathrm{E}+12$ & 14.9 & & 1.07 & \\
\hline & 573 & $5.42 \mathrm{E}-06$ & & $2.81 \mathrm{E}+12$ & 17.2 & & 0.95 & \\
\hline & 533 & $6.69 \mathrm{E}-06$ & & $1.81 \mathrm{E}+12$ & 12.3 & $1.00 \mathrm{E}-01$ & 0.76 & \\
\hline & 553 & $6.34 \mathrm{E}-06$ & & $1.79 \mathrm{E}+12$ & 12.3 & $3.16 \mathrm{E}-01$ & 0.71 & \\
\hline & 573 & $6.42 \mathrm{E}-06$ & & $2.19 \mathrm{E}+12$ & 12.3 & $7.80 \mathrm{E}-01$ & 0.88 & \\
\hline & 593 & $6.11 \mathrm{E}-06$ & & $2.69 \mathrm{E}+12$ & 12.3 & $3.95 \mathrm{E}+00$ & 1.03 & \\
\hline & 613 & $6.71 \mathrm{E}-06$ & & $3.72 \mathrm{E}+12$ & 12.3 & $3.06 \mathrm{E}+00$ & 1.56 & \\
\hline \multirow{8}{*}{$\mathrm{Cu}$} & 298 & $1.46 \mathrm{E}-06$ & & $4.50 \mathrm{E}+13$ & 157 & $3.00 \mathrm{E}-01$ & 4.11 & \multirow{8}{*}{ Staker \& Holt (1972) } \\
\hline & 523 & $1.70 \mathrm{E}-06$ & & $3.38 \mathrm{E}+13$ & 123 & $3.00 \mathrm{E}-01$ & 3.59 & \\
\hline & 673 & $2.10 \mathrm{E}-06$ & & $2.55 \mathrm{E}+13$ & 87.9 & $3.00 \mathrm{E}-01$ & 3.35 & \\
\hline & 773 & $3.17 \mathrm{E}-06$ & & $1.09 \mathrm{E}+13$ & 55.6 & $3.00 \mathrm{E}-01$ & 2.15 & \\
\hline & 823 & 3.37E-06 & & $7.50 \mathrm{E}+12$ & 47.5 & $3.00 \mathrm{E}-01$ & 1.58 & \\
\hline & 873 & $3.91 \mathrm{E}-06$ & & $5.25 \mathrm{E}+12$ & 33.9 & $3.00 \mathrm{E}-01$ & 1.28 & \\
\hline & 923 & $4.78 \mathrm{E}-06$ & & $4.88 \mathrm{E}+12$ & 27.9 & $3.00 \mathrm{E}-01$ & 1.46 & \\
\hline & 973 & $5.94 \mathrm{E}-06$ & & $3.19 \mathrm{E}+12$ & 21.3 & $3.00 \mathrm{E}-01$ & 1.18 & \\
\hline \multirow{6}{*}{$\mathrm{Fe}$} & 923 & $1.54 \mathrm{E}-05$ & & $1.87 \mathrm{E}+12$ & 18.4 & & 1.80 & \multirow{6}{*}{ Karashima et al. (1971) } \\
\hline & 973 & $1.02 \mathrm{E}-05$ & & $2.47 \mathrm{E}+12$ & 13.7 & $1.11 \mathrm{E}-01$ & 1.57 & \\
\hline & 1023 & $1.28 \mathrm{E}-05$ & & $1.73 \mathrm{E}+12$ & 9.4 & & 1.39 & \\
\hline & 1073 & $1.24 \mathrm{E}-05$ & & $1.32 \mathrm{E}+12$ & 6.5 & & 1.02 & \\
\hline & 1123 & $1.40 \mathrm{E}-05$ & & $2.92 \mathrm{E}+12$ & 4.8 & & 2.55 & \\
\hline & 973 & 7.79E-06 & & $6.55 \mathrm{E}+12$ & 39.2 & & 3.19 & \\
\hline
\end{tabular}




\begin{tabular}{|c|c|c|c|c|c|c|c|c|}
\hline & & 973 & $7.35 \mathrm{E}-06$ & $5.84 \mathrm{E}+12$ & 29.4 & & 2.68 & \\
\hline & & 973 & $8.41 \mathrm{E}-06$ & $3.04 \mathrm{E}+12$ & 24.5 & & 1.60 & \\
\hline & & 973 & $8.50 \mathrm{E}-06$ & $2.71 \mathrm{E}+12$ & 19.6 & & 1.44 & \\
\hline & & 973 & $1.05 \mathrm{E}-05$ & $2.31 \mathrm{E}+12$ & 13.7 & & 1.52 & \\
\hline & & 973 & $1.90 \mathrm{E}-05$ & $1.72 \mathrm{E}+12$ & 9.8 & & 2.05 & \\
\hline & & 873 & $2.10 \mathrm{E}-06$ & $1.25 \mathrm{E}+13$ & 107 & & 1.64 & \multirow{10}{*}{ Orlova \& Cadek (1973) } \\
\hline & & 873 & $2.21 \mathrm{E}-06$ & $9.66 \mathrm{E}+12$ & 93.4 & & 1.34 & \\
\hline & & 873 & $2.53 \mathrm{E}-06$ & $8.82 \mathrm{E}+12$ & 73.5 & & 1.39 & \\
\hline & & 873 & $2.92 \mathrm{E}-06$ & $6.56 \mathrm{E}+12$ & 48.4 & & 1.20 & \\
\hline & & 873 & $3.74 \mathrm{E}-06$ & $4.71 \mathrm{E}+12$ & 35.7 & & 1.10 & \\
\hline & & 773 & $1.13 \mathrm{E}-06$ & $2.15 \mathrm{E}+13$ & 219 & & 1.52 & \\
\hline & & 773 & $1.77 \mathrm{E}-06$ & $1.85 \mathrm{E}+13$ & 193 & & 2.04 & \\
\hline & & 773 & $1.46 \mathrm{E}-06$ & $2.03 \mathrm{E}+13$ & 171 & & 1.85 & \\
\hline & & 773 & $2.11 \mathrm{E}-06$ & $1.17 \mathrm{E}+13$ & 148 & & 1.54 & \\
\hline & & 773 & $1.93 \mathrm{E}-06$ & $1.24 \mathrm{E}+13$ & 129 & & 1.50 & \\
\hline & & 973 & $1.67 \mathrm{E}-05$ & $6.46 \mathrm{E}+11$ & 13.7 & $7.20 \mathrm{E}-02$ & 0.67 & \multirow{5}{*}{$\begin{array}{l}\text { Karashima, Iikubo, \& Oikawa } \\
\text { (1972), single crystal }\end{array}$} \\
\hline & & 973 & $8.04 \mathrm{E}-06$ & $1.01 \mathrm{E}+12$ & 24.5 & $5.40 \mathrm{E}+00$ & 0.51 & \\
\hline & & 973 & $2.25 \mathrm{E}-05$ & $4.37 \mathrm{E}+11$ & 9.8 & $1.43 \mathrm{E}-02$ & 0.61 & \\
\hline & & 873 & $1.92 \mathrm{E}-05$ & $7.55 \mathrm{E}+11$ & 22.5 & $3.60 \mathrm{E}-03$ & 0.91 & \\
\hline & & 1073 & $1.52 \mathrm{E}-05$ & $7.26 \mathrm{E}+11$ & 6.5 & $3.60 \mathrm{E}+00$ & 0.69 & \\
\hline \multirow{6}{*}{\multicolumn{2}{|c|}{$\mathrm{Fe}-4 \mathrm{Mo}$}} & 1021 & $5.66 \mathrm{E}-06$ & $4.79 \mathrm{E}+13$ & 98.0 & & 16.94 & \multirow{6}{*}{ Fucks \& Ilschner (1969) } \\
\hline & & 1021 & $6.76 \mathrm{E}-06$ & $2.51 \mathrm{E}+13$ & 68.3 & $3.60 \mathrm{E}-01$ & 10.63 & \\
\hline & & 1021 & $9.04 \mathrm{E}-06$ & $1.26 \mathrm{E}+13$ & 39.2 & $7.20 \mathrm{E}-02$ & 7.11 & \\
\hline & & 1098 & 7.65E-06 & $1.92 \mathrm{E}+13$ & 47.0 & & 9.17 & \\
\hline & & 1098 & $9.15 \mathrm{E}-06$ & $8.15 \mathrm{E}+12$ & 31.2 & & 4.66 & \\
\hline & & 1098 & $1.29 \mathrm{E}-05$ & $6.03 \mathrm{E}+12$ & 19.2 & $7.20 \mathrm{E}-02$ & 4.84 & \\
\hline \multirow{12}{*}{\multicolumn{2}{|c|}{ Type 304}} & 1023 & $6.00 \mathrm{E}-06$ & $4.59 \mathrm{E}+12$ & 120 & $1.81 \mathrm{E}+00$ & 1.72 & \multirow{4}{*}{$\begin{array}{l}\text { Kassner, Miller, \& Sherby } \\
\text { (1982) }\end{array}$} \\
\hline & & 1023 & $2.53 \mathrm{E}-06$ & $1.57 \mathrm{E}+13$ & 150 & & 2.49 & \\
\hline & & 1023 & $1.83 \mathrm{E}-06$ & $4.37 \mathrm{E}+13$ & 161 & & 4.99 & \\
\hline & & 1023 & $7.50 \mathrm{E}-07$ & $7.52 \mathrm{E}+13$ & 208 & & 3.53 & \\
\hline & & 1089 & $4.71 \mathrm{E}-06$ & $2.66 \mathrm{E}+12$ & 54 & & 0.78 & \multirow{8}{*}{ Cuddy (1970) } \\
\hline & & 1089 & $2.85 \mathrm{E}-06$ & $2.86 \mathrm{E}+12$ & 69 & & 0.51 & \\
\hline & & 1089 & $2.66 \mathrm{E}-06$ & $3.90 \mathrm{E}+12$ & 90 & & 0.65 & \\
\hline & & 1089 & $2.33 \mathrm{E}-06$ & $5.27 \mathrm{E}+12$ & 108 & & 0.77 & \\
\hline & & 1089 & $2.04 \mathrm{E}-06$ & $1.29 \mathrm{E}+13$ & 127 & & 1.65 & \\
\hline & & 977 & 3.33E-06 & $5.86 \mathrm{E}+12$ & 91 & $2.20 \mathrm{E}-03$ & 1.22 & \\
\hline & & 977 & $2.04 \mathrm{E}-06$ & $1.20 \mathrm{E}+13$ & 127 & & 1.53 & \\
\hline & & 977 & $2.01 \mathrm{E}-06$ & $2.58 \mathrm{E}+13$ & 172 & & 3.23 & \\
\hline \multirow{11}{*}{\multicolumn{2}{|c|}{ Type 316}} & 977 & $1.95 \mathrm{E}-06$ & $5.48 \mathrm{E}+13$ & 284 & $9.72 \mathrm{E}-02$ & 6.67 & \multirow{3}{*}{$\begin{array}{l}\text { Michel, Moteff, \& Lovell } \\
\text { (1973) }\end{array}$} \\
\hline & & 1033 & $2.60 \mathrm{E}-06$ & $3.79 E+13$ & 219 & & 6.17 & \\
\hline & & 1089 & $2.94 \mathrm{E}-06$ & $2.75 \mathrm{E}+13$ & 172 & & 5.05 & \\
\hline & & 977 & $1.60 \mathrm{E}-06$ & $2.40 \mathrm{E}+13$ & 137 & $2.02 \mathrm{E}-03$ & 2.40 & \multirow{8}{*}{ Challenger \& Moteff (1973) } \\
\hline & & 977 & $2.20 \mathrm{E}-06$ & $2.60 \mathrm{E}+13$ & 123 & $1.19 \mathrm{E}-03$ & 3.58 & \\
\hline & & 1005 & $1.70 \mathrm{E}-06$ & $1.60 \mathrm{E}+13$ & 151 & $1.26 \mathrm{E}-03$ & 1.70 & \\
\hline & & 1005 & $2.60 \mathrm{E}-06$ & $2.00 \mathrm{E}+13$ & 124 & $2.59 \mathrm{E}-03$ & 3.25 & \\
\hline & & 1005 & $3.10 \mathrm{E}-06$ & $1.20 \mathrm{E}+13$ & 96 & $5.76 \mathrm{E}-04$ & 2.33 & \\
\hline & & 1089 & $3.00 \mathrm{E}-06$ & $9.40 \mathrm{E}+12$ & 83 & $1.08 \mathrm{E}-03$ & 1.76 & \\
\hline & & 1089 & 4.40E-06 & $5.20 \mathrm{E}+12$ & 69 & $2.81 \mathrm{E}-03$ & 1.43 & \\
\hline & & 1089 & $4.50 \mathrm{E}-06$ & $5.70 \mathrm{E}+12$ & 55 & $8.28 \mathrm{E}-04$ & 1.60 & \\
\hline \multirow{5}{*}{\multicolumn{2}{|c|}{$\begin{array}{l}\text { High } \\
\text { martensitic } \\
\text { steel }\end{array}$}} & 823 & $4.99 \mathrm{E}-07$ & $3.60 \mathrm{E}+13$ & 165 & $2.16 \mathrm{E}-06$ & 1.12 & Straub et al. (1993), X20 \\
\hline & & 823 & $7.26 \mathrm{E}-07$ & $1.02 \mathrm{E}+13$ & 120 & $9.43 \mathrm{E}-08$ & 0.46 & $\begin{array}{l}\text { Aghajani Bazazi (2009), } \\
\text { X20 }\end{array}$ \\
\hline & & 873 & $7.50 \mathrm{E}-07$ & $1.10 \mathrm{E}+14$ & 177 & 3.60E-04 & 5.16 & $\begin{array}{l}\text { Sawada et al. (1997), } \\
\text { Type } 91 \text { plate }\end{array}$ \\
\hline & & 923 & $3.19 \mathrm{E}-07$ & $3.57 \mathrm{E}+14$ & 118 & $3.60 \mathrm{E}-05$ & 7.12 & Dudko et al. (2017), P92 \\
\hline & & 923 & $4.30 \mathrm{E}-07$ & $1.50 \mathrm{E}+14$ & 140 & $2.16 \mathrm{E}-05$ & 4.03 & $\begin{array}{l}\text { Dudova et al. (2012), } \\
\text { Co modified P92 }\end{array}$ \\
\hline
\end{tabular}

\section{Copyrights}

Copyright for this article is retained by the author(s), with first publication rights granted to the journal.

This is an open-access article distributed under the terms and conditions of the Creative Commons Attribution license (http://creativecommons.org/licenses/by/4.0/). 